\title{
Real Time Aircraft Atypical Approach Detection for Air Traffic Control
}

\author{
Gabriel Jarry*, Daniel Delahaye*, Stephane Puechmorel*, Eric Feron ${ }^{\dagger}$ \\ * ENAC, Université de Toulouse, 7 Avenue Edouard Belin, 31400 Toulouse \\ Email: \{gabriel.jarry, daniel.delahaye, stephane.puechmorel\}@enac.fr \\ $\dagger$ King Abdullah University of Science and Technology, \\ Division of Electrical, Computer and Mathematical Science and Engineering, \\ on leave from Georgia Institute of Technology, \\ Thuwal, 23955, Saudi Arabia \\ Email: eric.feron@kaust.edu.sa
}

\begin{abstract}
In this paper, a complete tool for real-time detection of atypical energy behaviors of airplanes is presented. The methodology extends in real time an existing offline process using Dubins trajectories as a predictor of the remaining distance to the runway threshold. Two major contributions are presented in this paper. First, a real-time measure of the aircraft energy behaviour is defined, indicating whether the aircraft is in good condition to intercept the extended runway centreline from its current position. Secondly, a 2D trajectory suggestion is given, allowing safe management of the approach path according to atypical criteria of historical data. Finally, this document proposes a comprehensive tool for air traffic controllers, which is a major step forward in understanding, becoming aware of and resolving critical situations that could lead to accidents.
\end{abstract}

Index Terms-Approach Path Management, Atypical Flight Event, Non-Compliant Approach, Real Time, Anomaly Detection, Functional Principal Component Analysis, Unsupervised Learning, Dubins Path,

\section{INTRODUCTION}

\section{A. Operational Motivations}

Approach and landing accidents (i.e. accidents that occur during the initial approach, intermediate approach and landing phases) account for 47 per cent of the total number of accidents and 40 per cent of fatalities each year. In addition, a large majority of accidents show significant differences from nominal approaches such as atypical airspeed or atypical altitude [1]. In addition, airport Terminal Manoeuvring Areas and Control Traffic Regions are characterised by a dense and highly complex air traffic flow. This complexity is likely to increase as IATA predicts that the number of air passengers worldwide will rise from around 4 billion today to 7,8 billion in 2036 [2]. Analyzing and gaining a better understanding of flight operational issues like atypical behaviors would benefit air traffic managers and flight operators.

In order to meet the safety requirements of the International Civil Aviation Organization, the French Directorate of Civil Aviation launched a national safety programme in 2006, which is currently divided into three national safety programmes published for the period 2009-2013: [3], 2013-2018: [4] and 2018-2023: [5]. The risk portfolio [6] distinguishes between undesirable events such as unstabilized approaches, and ultimate events such as control flights into terrain, or runway excursions. Undesirable events can lead to final events and thus compromise safety or reduce aerodrome capacity. Their identification and detection is an important issue.

Unstabilized approaches have been observed in several accidents, such as that of Air Nostrum flight 8313 on July 30, 2011, where the aircraft suffered structural damage following a hard landing at Barcelona airport [7]. Peak descent rates in excess of $3000 \mathrm{ft} / \mathrm{min}$ were recorded and the aircraft crossed the runway threshold at $315 \mathrm{ft}$, where the nominal reference height $(\mathrm{RDH})$, i.e. the nominal height above the runway threshold, is approximately 50ft. Another example is the July 6, 2014 crash of Asiana Airline Flight 214 at San Francisco Airport, which resulted in 3 fatalities and 185 injuries [8]. The plane was recorded with a very low speed on final approach and finally stalled before crashing.

Various studies have been conducted to determine the precursors of the unstabilized approach. In particular, Jiao et al. [9] have shown that speed is the main source of nonstabilization, followed by localizer and glide deviations.

\section{B. Previous Related Works}

Particular atypical situations called "Glide Interception From Above" (GIFA have been identified as undesirable. These situations are critical because of the potential difficulties in managing aircraft energy and because aircraft are neither designed nor certified to intercept glide from above.

To improve safety and reduce the number of GIFAs, an online detection tool has been implemented at Charles-DeGaulle airport and used by the Air Traffic Controllers in real time. It consists of four 3D volumes using the Area Proximity Warning (APW) described in 1. The first three volumes are alert volumes, the ATC $\$$ warn pilots that they are too high on the glide path. The last volume is a decision volume, where the ATC and pilots must decide whether to continue or abort the approach. The results of the experiments are positive since today the GIFAs are detected and appropriate action is taken. About 5 flights out of the 700 per day trigger an alarm and in about half of the cases, the GIFAs suggest a recovery slope as recommended. Nevertheless, this tool focuses only on potential energy. 


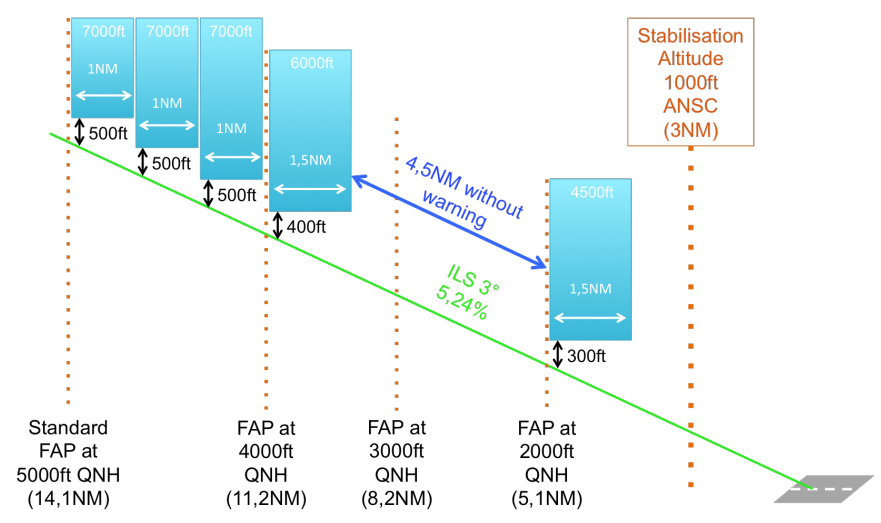

Figure 1. Illustration of the Glide Interception From Above detection implemented at Charles de Gaulle airport. 3D volumes have been set up to detect when an aircraft is too high on the glide path. A recovery plan is proposed. If it is still too high on the glide path further downstream, the air traffic controllers suggest a go-around.

Previous work [10] has proposed using unsupervised learning to provide post-operational detection of atypical behaviour in the total energy of the aircraft. This methodology proposed by Jarry et al. is based on the combination of a sliding window, an information geometry tool called functional principal component analysis and outlier scoring as illustrated in Figure 2 A portion of the flight is then considered atypical (and given a score of 1) if the total energy of the aircraft (computed in the runway referential using the ground speed, the vertical speed, and the height) does not behave in terms of norm and variation like other flights at a particular distance from the runway threshold. In other word, the score is inversely proportional to the statistical frequency in the learning data set. The result is a continuous score between 0 and 1 along the trajectory. The score is 0 if the underlying segment is similar to a large number of other segments at the same distance from the runway threshold. The score is 1 if it is a totally unknown energy segment, and it is then called atypical energy behaviour. This is a post-operational methodology that requires the entire trajectory to be applied. It can not be applied directly in real time because the remaining trajectory to the runway threshold is unknown. This methodology has been validated with flight data records from airline safety offices and safety events [11]. It showed a significant correlation between the atypical energy behavior and airline safety events. In particular, while the unstabilized approach represents between 3 and $4 \%$ of typical flights, it accounts for $50.4 \%$ of atypical flights between 5NM and the runway threshold. In addition, the methodology was compared to the detection of anomalies with the help of generative adversarial networks [12] in a similar way to an autoencoder. The FPCA methodology presents similar results with the advantage of giving a local atypicality score. Moreover, it seems more flexible as it is deterministic and not subject to the potential problem of neural network convergence.

Other projects and research have been conducted to analyze anomalies, including anomalies in the onboard data. In particular, $\mathrm{Li}$ et al. have developed a very similar approach based on PCA dimensional reduction and DBSCAN outlier scoring [13]-[15]. The methodology proposed by Jarry et al.

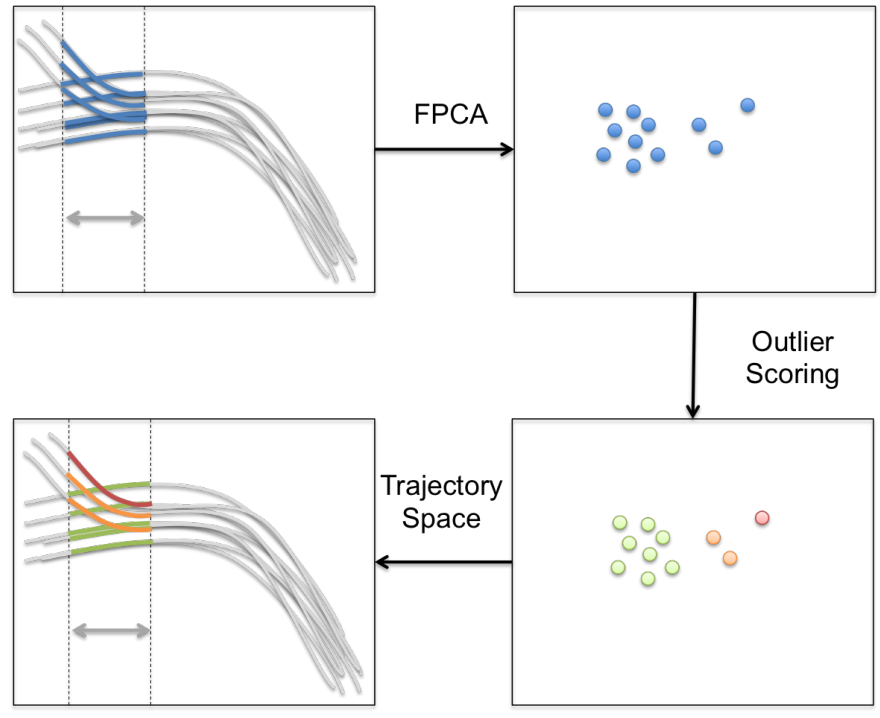

Figure 2. Illustration of the methodology for detecting atypical trajectories. A sliding window is applied on all trajectories. The dimension is then reduced by applying a Functional Principal Component Analysis decomposition on the portions of such trajectories. An outlier detection and scoring is applied on the decomposition vector space, which allows to assign to each trajectory portion a score between 0 and 1, determining the local atypicality.

takes up the same philosophy but improves it by using a FPCA that integrates the underlying functional nature of the trajectories, and the use of a sliding window that allows to localize the atypicality. Finally, the distance to the remaining runway threshold, which is more appropriate for energy management, is used as a reference instead of time. In addition, work has also been carried out on the detection of anomalies in on-board data using multiple kernel [16], active learning [17], or recurrent neural network methods [18]. In addition, Andreu et. al. have developed an on-board methodology [19] to propose recovery trajectories when aircraft present overenergy. The roles of cockpit alerting systems are multiple, but all present significant human factor issues and must be designed accordingly [20].

Recently, Singh et al. [21] proposed real-time detection of unstable approaches. Their detection philosophy has similarities with the FPCA process. Indeed, they use the data set to estimate upper and lower limits of parameters, while Jarry et al. [10] propose to determine an atypical coefficient based on clusters and their distribution. However, there are major differences. First, the upper and lower limits do not account for potential atypical variations within these limits, which are detected with the FPCA process. Second, they address a simplified problem, since they focus only on the last phase of flight, where the aircraft is aligned with the extended runway centreline. Third, they assume a normal distribution assumption, which may not be true for all parameters. In particular, the ground speed trajectories can easily be clustered into two groups. Indeed, some flights adopt their approach speed very early, while others wait until the very last moment to reduce speed, which implies at least a bi-modal distribution. 


\section{Contribution}

This paper presents two major contributions. These contributions are based on the assumption that energy models [10] are available and illustrate how they can be used in a real-time framework. The first contribution is the real time extension of the post-operational methodology [10] using Dubins' path as an estimator of the remaining distance. Second, a methodology to generate a typical 2D energy management trajectory is proposed while the aircraft is flying downwind or on base leg. At the end, a complete real-time atypical trajectory detection tool for Air Traffic Controllers is presented with two modes depending on the position of the aircraft. Before intercepting the localizer, the aircraft is usually radar vectored. At this stage, the tool is in a suggestion phase and gives two types of information. First, it estimates the current status of the aircraft considering a direct trajectory to intercept the localizer at the interception chevrons. Then, if this trajectory presents a high energy, a suggested trajectory is calculated. Finally, when the aircraft has intercepted the localizer, the tool switches to an alerting phase, giving the current status of the aircraft energy management.

The paper is divided into three parts. First, the mathematical background around Dubins' paths and optimal control is presented. In addition, the real-time extension and the 2D generation process using Dubins paths are detailed. Second, the methodology and results are illustrated on different case studies, in particular the Asiana Airline Flight 214 at San Francisco airport on July 6, 2013, the Pegasus Airlines Flight 2193, which overran Istanbul runway on February 5, 2020, the Hermes Airline Flight 7817, which overran Lyon SaintExupéry runway on March 29, 2013, and the Air India Express Flight 1344, which overan Calicut airport on August 07, 2020.

\section{Methodology And Backgrounds}

\section{A. Dubin curves problem for trajectory generation}

The real-time extension of the atypicality score triggers a major problem. To calculate the atypicality score, the remaining distance to the runway threshold must be known. This distance is well known if the aircraft is aligned with the runway extension axis. However, if the aircraft is still flying downwind or on base leg, the distance remaining to the threshold is unknown. A simple estimate of the remaining distance can be obtained using Dubins curves.

Key point of Dubin curves, is shortest path between A and $\mathrm{B}$ when contraint by maximum curvature and a given direction of the line at A and B. The general solution was published by Dubins in 1958 [22]. It was also proved by Boissonnat et al. [23] by applying the principle of maximum Pontryagin [24].

The problem can be formulated as an optimal control problem, where the state variables are $x, y, \theta$, the control variable is $u, \mathrm{R}$ is the minimum turning radius, and $\mathrm{t}$ is the curvilinear abscissa :

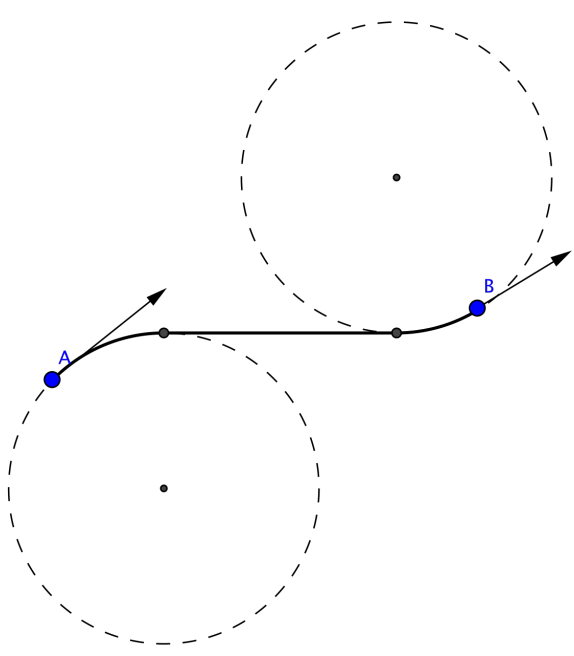

Figure 3. Illustration of a Dubins path between two points A and B. The solution here is RSL: a right turn, then a straight line, and finally a left turn.

$$
\begin{array}{ll}
\min _{u} & t_{f}=\int_{0}^{t_{f}} 1 \mathrm{~d} t \\
\text { s.t. } & \dot{x}(t)=\cos \theta(t), x(0)=x_{0}, x\left(t_{f}\right)=x_{f}, \\
& \dot{y}(t)=\sin \theta(t), \quad y(0)=y_{0}, y\left(t_{f}\right)=y_{f}, \\
& \dot{\theta}(t)=u(t), \quad \theta(0)=\theta_{0}, \theta\left(t_{f}\right)=\theta_{f}, \\
& \mid u(t)] \leq \frac{1}{R}, \quad t \in\left[0, t_{f}\right]
\end{array}
$$

The solution is one of the following six combinations: RSR, RSL, LSR, LSL, RLR, LRL. Where R and L represent respectively a right and left turning arc at maximum curvature, and $\mathrm{S}$ a straight line segment. A simple illustration if given in Figure 3 where the solution is RSL : a right turn, then a straight line, and finally a left turn. It has been applied to various fields such as robotics for example. Buil et al. applied Dubins' method to find the shortest path for nonholonomical robots [25]. Furthermore, it has been extended to 3D by Chitsaz et al. referred as to Dubins' plane [26].

\section{B. Real-time atypical scoring methodology}

Returning to the real-time extension problem, the goal is to estimate the remaining distance to the runway threshold, consequently a 2D path is sufficient for this evaluation. To ensure this assumption, the real remaining distance is compared with the estimated remaining distance using Dubin curves over 1600 radar data approaches. In Figure 5 are illustrated the box-plots of the differences between estimated and actual remaining distance between 15NM and 40NM that are computed every $1 \mathrm{NM}$.

The error observes is negligible (under 1NM absolute error) from $15 \mathrm{NM}$ to $21 \mathrm{NM}$. It then, underestimates the remaining distance and usually gives a lower bound, which is the expected behavior. Only very few over estimations are observed and generally due to non-compliant approaches associated 


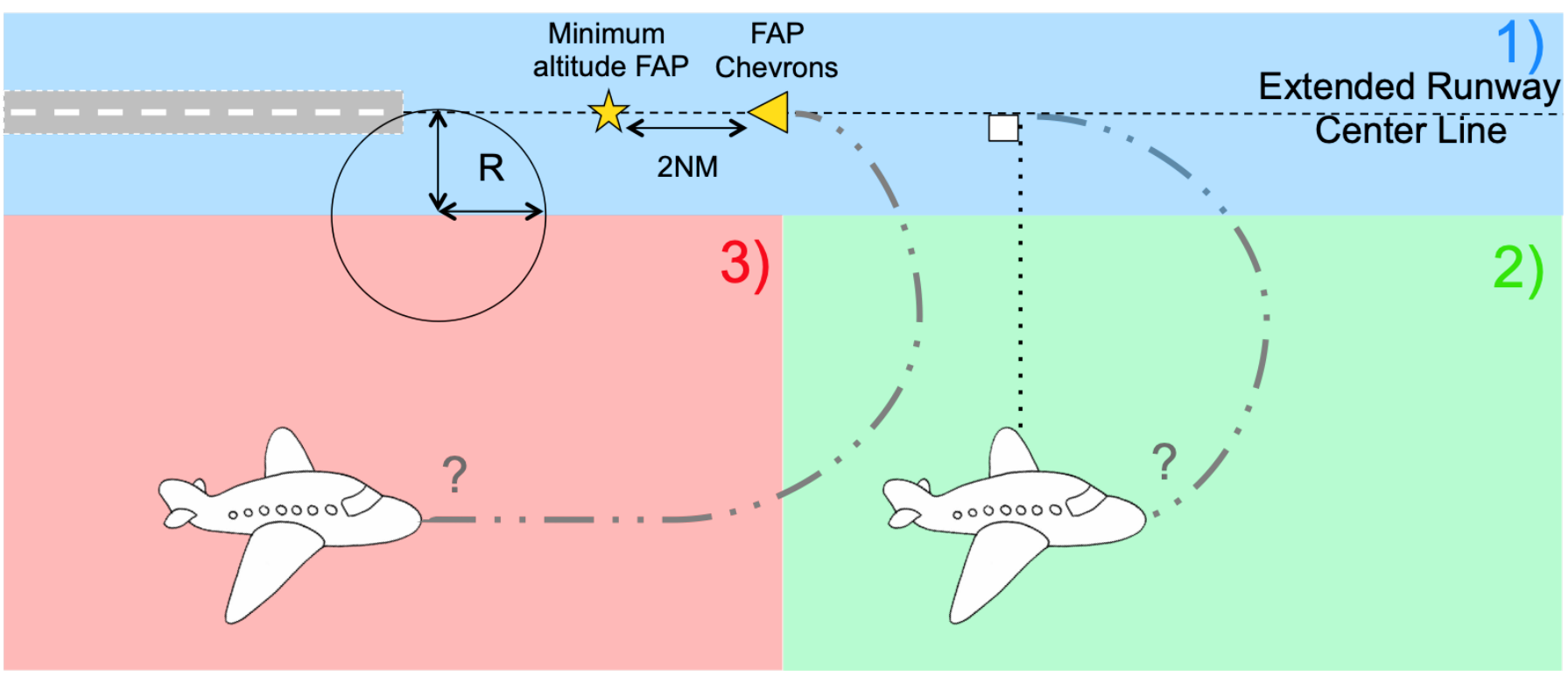

Figure 4. Illustration of the different cases of the methodology. different situation. Case 1) in blue, corresponds to the portions of the trajectory where the aircraft is on the localizer (distance to the localizer less than one turning radius). Case 2) in green, corresponds to the portions of trajectory where the aircraft is at on base or downwind leg but beyond the perpendicular to the chevrons. Case 3) in red, corresponds to the portions of trajectories where the aircraft is in downwind leg, before the perpendicular to the chevrons.

with trajectory shortening. The use of Dubin curves seems to be accurate.

The following assumptions will be applied. First, the aircraft is considered to have a constant ground speed of $180 \mathrm{kts}$ and turns with a bank angle of $25^{\circ}$, which implies a turning radius of 1.01NM. This is a lower bound assumption for the ground speed to obtain a lower bound estimation of the remaining distance. The bank angle is the usual bank angle recommended for turns. Three situations, illustrated in Figure 4, will be considered to calculate the remaining distance:

1) The aircraft is aligned with the runway extended centerline. The aircraft will be considered aligned with the runway extended centreline if the distance between the current position and its projection above the runway extended centreline is less than the minimum turning radius.

2) The aircraft is not aligned with the runway extended centreline and its orthogonal projection on the runway extended centreline is located after the intercept chevrons of the minimum altitude FAP.

3) The aircraft is not aligned with the runway extended centreline, and its orthogonal projection on the runway extended centreline is located before the FAP minimum altitude intercept chevrons.

In situation 1), the remaining distance to the runway threshold is assumed to be the distance to the orthogonal projection plus the distance from the projection to the runway threshold. In situation 2), the length of the Dubins curve from the current position with the current heading to the orthogonal projection with the runway heading is calculated and added to the distance from the projection to the runway threshold. Finally, in situation 3), the length of the Dubins curve from the current position with the current heading to the FAP chevrons with the runway heading is calculated and added to the distance between the FAP chevrons and the runway threshold.

When the estimated remaining distance is calculated, it is then easy to apply the scoring on the appropriate window, as proposed in the post-operational methodology [10]. In summary, the post-operational method consists of applying a functional principal component analysis and an atypical scoring on a sliding window, as shown in figure 2. At each point, the trajectory is given a score between 0 and 1 .

In summary, there are two ways to determine the remaining distance depending on the aircraft situation. When the aircraft has not yet intercepted the runway centreline, the distance is estimated by using Dubins curves. Otherwise, the remaining distance correspond to a straight line to the runway threshold. Finally, this distance is used to compute the atypical coefficient by applying the corresponding sliding window atypical energy model.

\section{Suggested trajectory methodology}

The trajectory generation process only addresses highenergy cases where the aircraft has not intercepted the extended runway centreline. Low-energy cases are not studied here. Indeed, when the atypicality is due to high energy, the idea is to give a longer trajectory in order to allow easier dissipation of the excess of energy. Conversely, when a low energy is detected, the idea is not to shorten the trajectory, so only the atypicality information is given to allow a better situation awareness. Indeed, the aircraft is usually operating in a traffic flow and a shortening of the trajectory could lead to the previous aircraft catching up. The good mitigating strategy would be to maintain the energy level until it returns to nominal. 


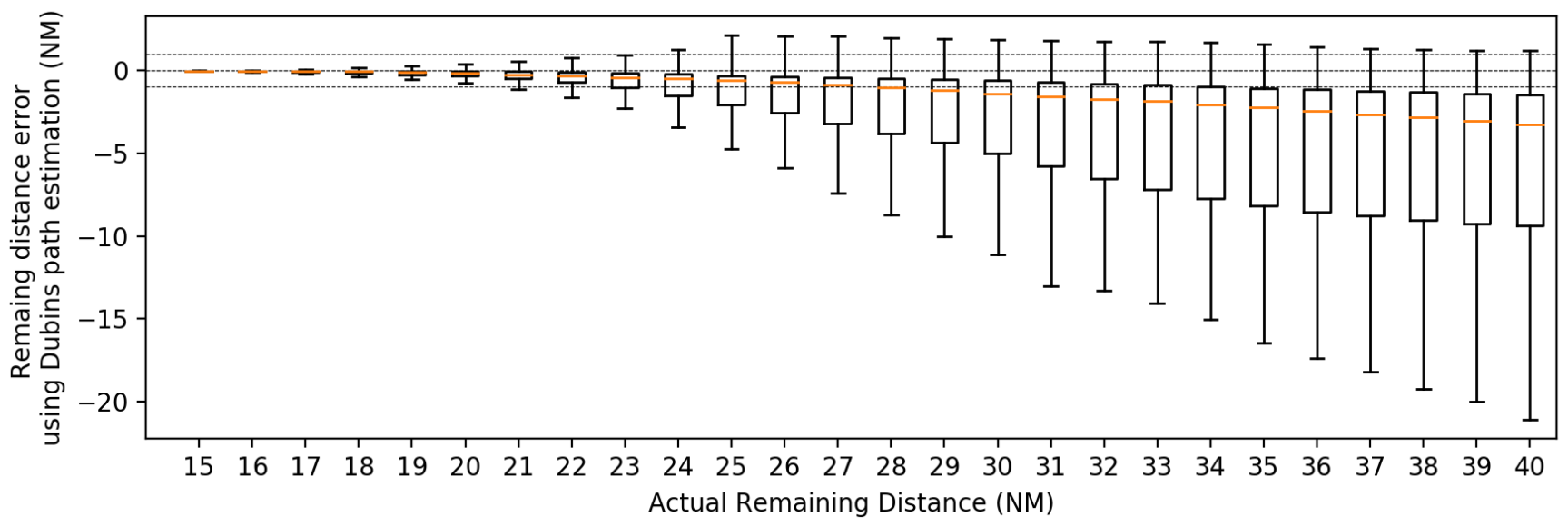

Figure 5. Box plot of the difference between estimated and real remaining distance between $15 \mathrm{NM}$ and $40 \mathrm{NM}$ (computed every $1 \mathrm{NM}$ over 1600 radar trajectories)

The generation process is simple; the point of interception of the localizer is gradually moved away from the runway threshold until a suitable atypicality level is reached. At each stage, the current energy state is evaluated using Dubins curves. The generation process is carried out if the coefficient of the current state is greater than 0.2 and the process is stopped if such a coefficient on the generated trajectory is less than 0.05 .

\section{Summary}

This paragraph details how to apply the methodology in real time mode or in replay mode as for the four following use cases.

Let's consider that the aircraft is in downwind leg (situation 2) or 3) in Figure 2). Its last positions are known but the next positions are unknown. In a replay mode, the next positions are voluntarily hidden. Here is the process to apply at every time step:

- With the current position and direction compute the estimated curve with the methodology presented in Section III-B and deduce the estimated remaining distance.

- Apply an energy model to obtain the atypicality score for this estimated trajectory with the estimated remaining distance.

- If the trajectory presents an atypicality due to high energy, apply the methodology presented in section II-C to obtain the trajectory suggestion. Otherwise stop there and wait for the next time step.

Let's now consider that the aircraft is now in situation 1) in Figure 2. Only the two first steps presented above are applied.

\section{STUDY}

The purpose of this section is to illustrate the use of the tool and its functionalities. The analysis of four air crashes in replay mode is presented : the Asiana Airline Flight 214 at San Francisco airport on July 6, 2013, the Pegasus Airlines Flight 2193, which overran Istanbul runway on February 5, 2020, the Hermes Airline Flight 7817, which overran Lyon
Saint-Exupéry runway on March 29, 2013, and the Air India Express Flight 1344, which overan Calicut airport on August 07, 2020.

For each crash, snapshots at certain moments of the trajectory will be presented. They illustrate the algorithm's behavior and the information it could have transmitted to the air traffic controller. The coefficient displayed at the top of each snapshot always corresponds to the direct trajectory to the point of interception. If the aircraft is in suggestion phase with high energy an alternative trajectory will be proposed, otherwise only the energy atypical information will be given. Additionally, the energy model used was previously built on a large data set (more than 15000 trajectories).

\section{A. Asiana flight 214}

On July 6, 2013, a Boeing 777-200ER operating Asiana Airlines Flight 214 struck a seawall at San Francisco International Airport (SFO) in San Francisco, California. Three passengers were fatally injured; 40 passengers were seriously injured. The aircraft was destroyed by the force of the impact and a post-crash fire. [8].

The flight was vectored for a visual approach to Runway 28L and intercepted the final approach track at an altitude slightly above the desired $3^{\circ}$ glide path. After accepting air traffic control's instruction to maintain a speed of 180 knots at $5 \mathrm{~nm}$ from the runway, the crew mismanaged the aircraft's descent and the aircraft was well above the $3^{\circ}$ glide path. In an attempt to increase the aircraft's rate of descent and capture the desired glide path, the pilot flying $(\mathrm{PF})$ selected an autopilot (A/P) mode (speed of flight level change (FLCH SPD)) that, instead, caused the autopilot system to initiate a climb because the aircraft was below the selected altitude. The $\mathrm{PF}$ disconnected the $\mathrm{A} / \mathrm{P}$ and moved the thrust levers to idle, causing the autothrottle (A/T) to go into HOLD mode, a mode in which the $\mathrm{A} / \mathrm{T}$ does not control airspeed.

At 500 feet above the airport elevation, the stabilization altitude, the precision approach path indicator (PAPI) would have shown that the aircraft was slightly above the desired 


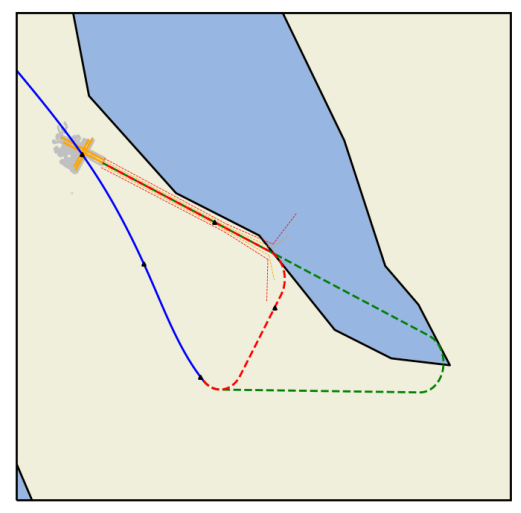

a)

\section{1:19:25 - Atypical Coefficient: 1.0}

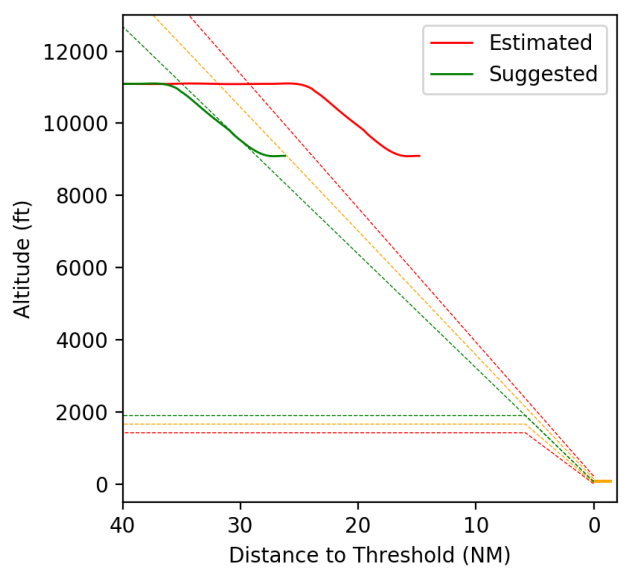

b)

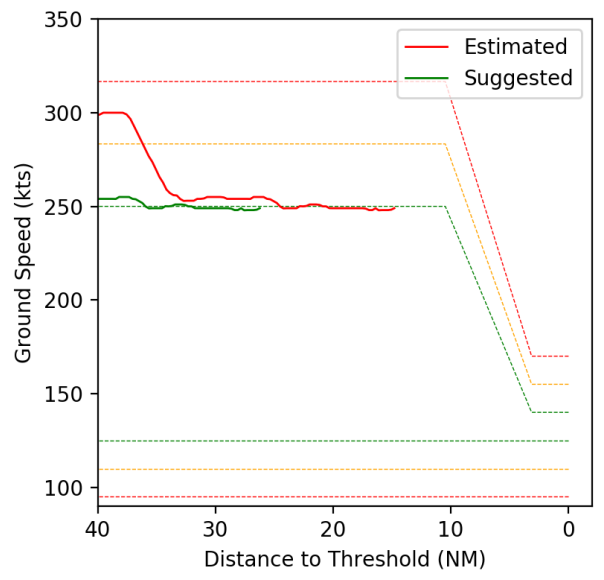

c)

Figure 6. Illustration of the Asiana Airline Flight 214. Figure a) represents the 2D trajectory, Figure b) illustrates the altitude profile, and Figure c) the ground speed profile. The plane is here in downwind leg (a). The tool indicates that a direct to the interception chevrons is critical (in red) and would cause the plane to be in over-energy due to high potential energy figure (a). The tool suggests a trajectory extending the tailwind leg (in green).

\section{1:23:29 - Atypical Coefficient: 0.05}

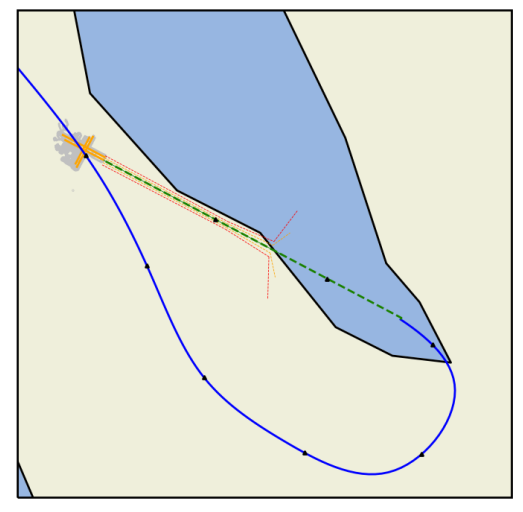

a)

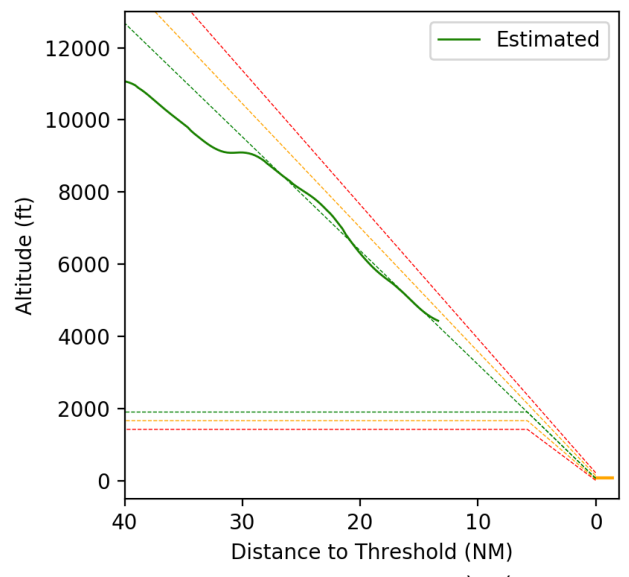

b)

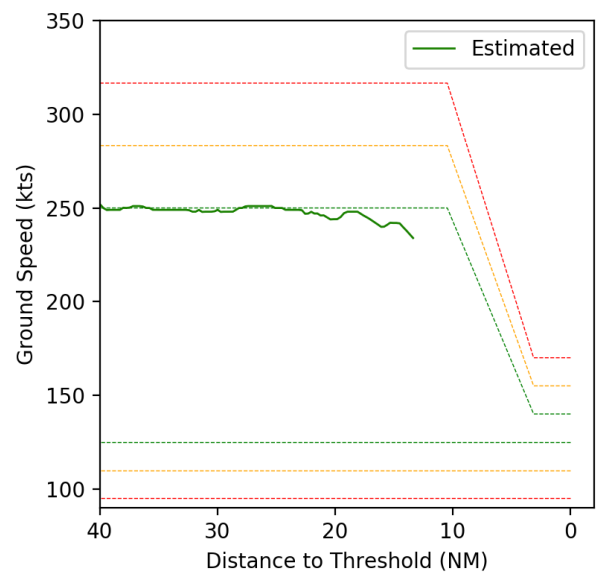

c)

Figure 7. Illustration of the Asiana Airline Flight 214 crash. Figure a) represents the 2D trajectory, Figure b) illustrates the altitude profile, and Figure c) the ground speed profile. The plane has just intercepted the runway centerline (a) and is in good condition, it is on the glide path (b) and presents a nominal speed (c).

glide path. The airspeed had just reached the correct approach speed of 137 knots. However, the thrust levers were still at idle, and the rate of descent was about 1200 feet per minute, well above the theoretical descent rate of about $700 \mathrm{fpm}$. The aircraft subsequently descended below the desired glide path and the airspeed continued to decrease. At about 200 feet, the flight crew became aware of the low airspeed and the low trajectory but did not initiate a go-around until the aircraft was below 100 feet, at which point the aircraft did not have the performance necessary to perform a go-around.

On-board data, available on the NSTB website, was used to study this crash. Only the parameters available on the ground (ground speed, vertical speed and altitude) are used by the algorithm .The study of this crash allows to highlight two key points of the algorithm. First, the use when the aircraft is downwind, allows to alert of the aircraft status in the case of a radar vectoring for example. Second, the ability to detect atypical variations within acceptable limits.

At 11:19:25 the aircraft is downwind, perpendicular to the intercepting chevrons. The atypicity score for a direct hit to the chevrons is maximum (1.0). The aircraft has a ground speed of 250kts, and is very high on the plane. The suggested trajectory mode proposes to extend the trajectory to intercept the runway centerline further (see Figure 6). At 11:23:29, the aircraft intercepted the runway centreline after an extended downwind leg. The atypical coefficient returned to nominal values. The plane is very slightly above the glide path with a speed of 240 kts ground speed (see Figure 7) At 11:26:09, the 


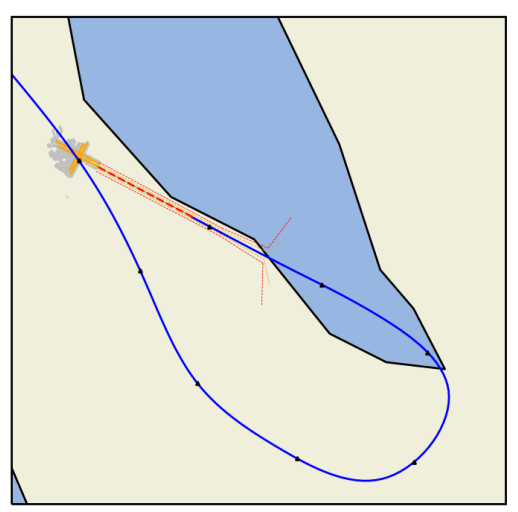

a)

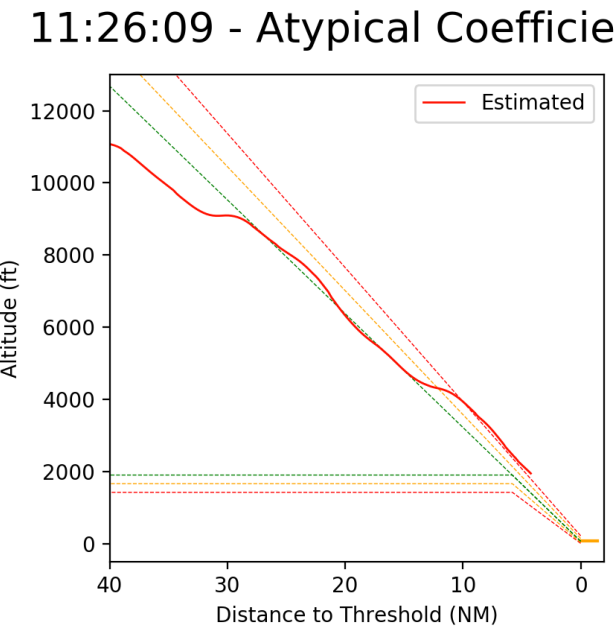

b)

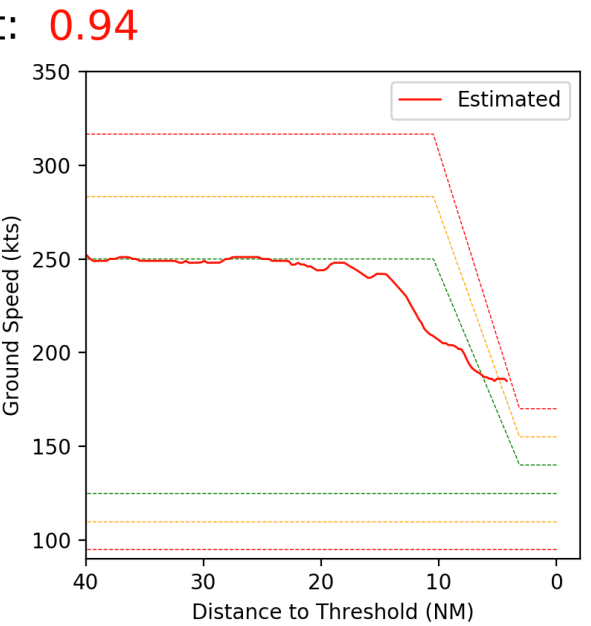

c)

Figure 8. Illustration of the Asiana Airline Flight 214 crash. Figure a) represents the 2D trajectory, Figure b) illustrates the altitude profile, and Figure c) the ground speed profile. The aircraft is $5 \mathrm{NM}$ from the runway threshold (a), above the glide path (b) with a ground speed of $180 \mathrm{kts}$ due to air traffic constraints (c). The plane is in over-energy due to both high potential and kinetic energy.

\section{1:27:25 - Atypical Coefficient: 0.97}

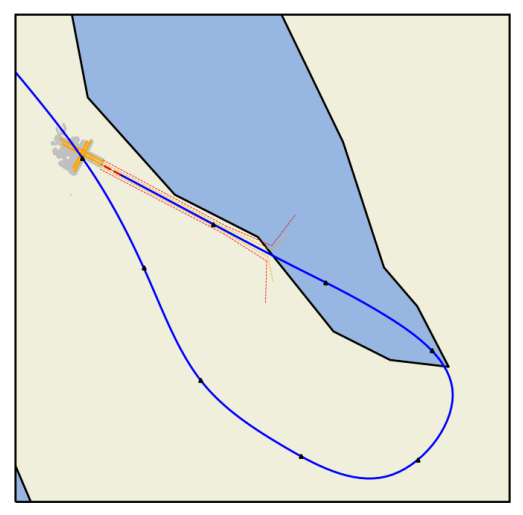

a)

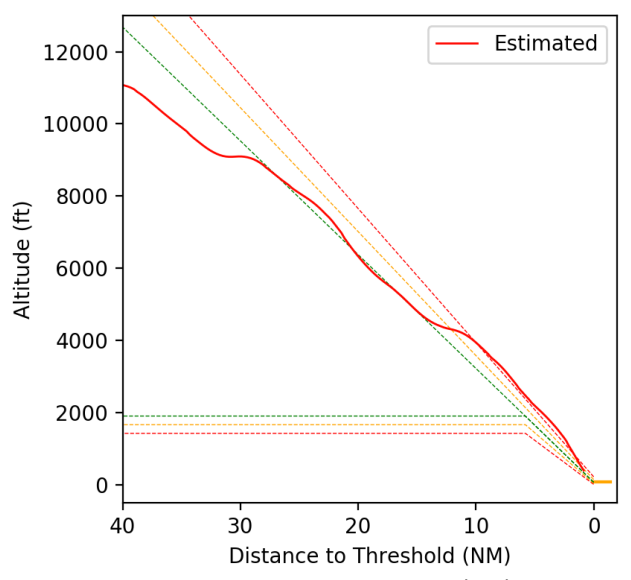

b)

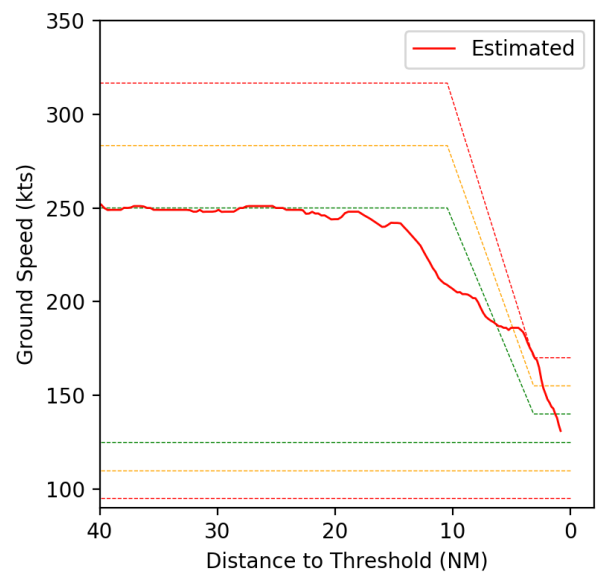

c)

Figure 9. Illustration of the Asiana Airline Flight 214 crash. Figure a) represents the 2D trajectory, Figure b) illustrates the altitude profile, and Figure c) the ground speed profile. The plane is at 500ft ground level, its speed (c) and altitude (b) have returned to nominal values but its energy variation is atypical (with a coefficient of 0.97) and directs it towards an under-energy

aircraft is $5 \mathrm{NM}$ from the runway threshold, at $180 \mathrm{kts}$ ground speed (ATC constraint) and above the theoretical glide path. The atypicality is high (0.94), and the aircraft is showing an over-energetic condition (see Figure 8). At 11:27:25, the aircraft is at 500ft ground level on glide path and at approach speed. However its energy variation is atypical and it has an atypical score of 0.97 which will not decrease for the rest of the final (see Figure 9p.

This case is very interesting because the aircraft has switched from high energy to low energy. Traditional methods with a high and a low bound do not take into account the sudden and atypical variations. Thus, during a certain period of time the aircraft could be considered in a nominal phase when it is not. Its abrupt energy variation is atypical and could have been detected with this type of tool.

\section{B. Pegasus Airlines flight 2193}

On February 5, 2020, the Boeing 737-800 of Pegasus Airlines flight 2193 from Izmir suffered a runway overrun on landing at Sabiha-Gökçen Airport in Istanbul, Turkey and broke into three parts [27], [28]. Three people were killed, 179 injured and the plane was destroyed. It comes less than a month after another Boeing 737 from the same company overran the runway at the same airport.

The journey from Adnan-Menderes Airport in Izmir to Istanbul went without a hitch. Around 18:30 local time (15:30 UTC), the plane attempted to land at Istanbul-Sabiha Gökçen in heavy rain and with a strong tail wind. A thunderstorm with 


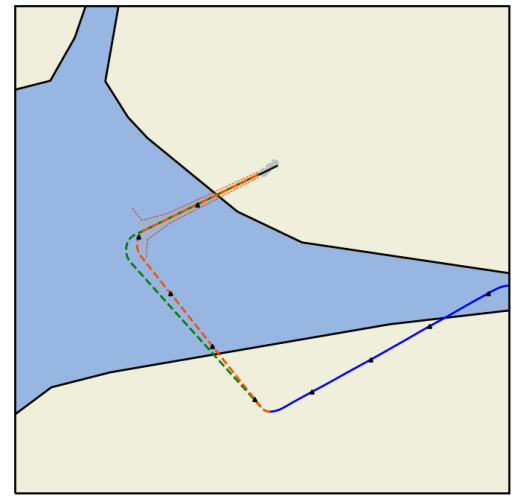

a)

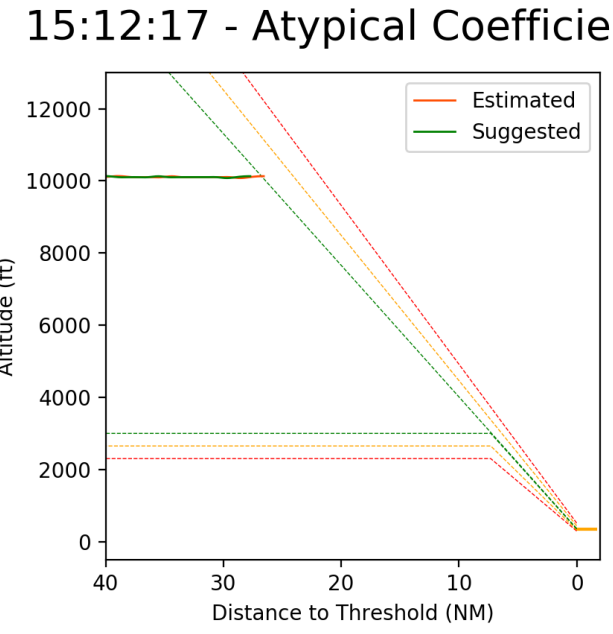

b)

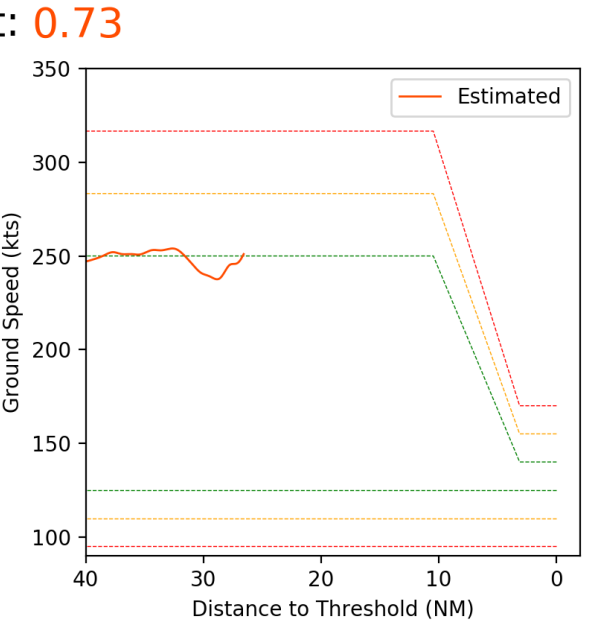

c)

Figure 10. Illustration of the Pegasus Airline Fight 2193 crash. Figure a) represents the 2D trajectory, Figure b) illustrates the altitude profile, and Figure c) the ground speed profile. The plane turns in base leg (a). Its ground speed increases (c) and it passes over the glide path (b).The tool suggests to slightly lengthen the track (in green).

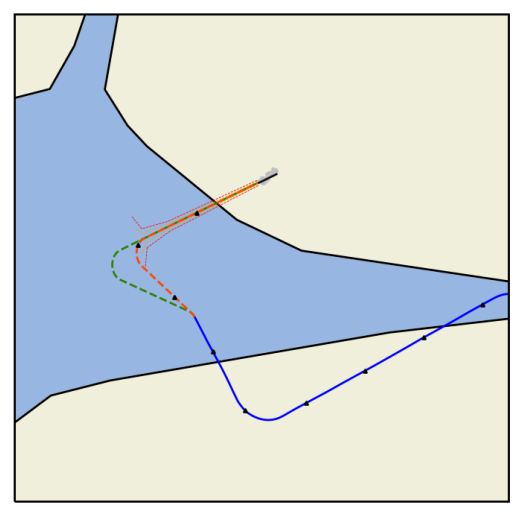

a)

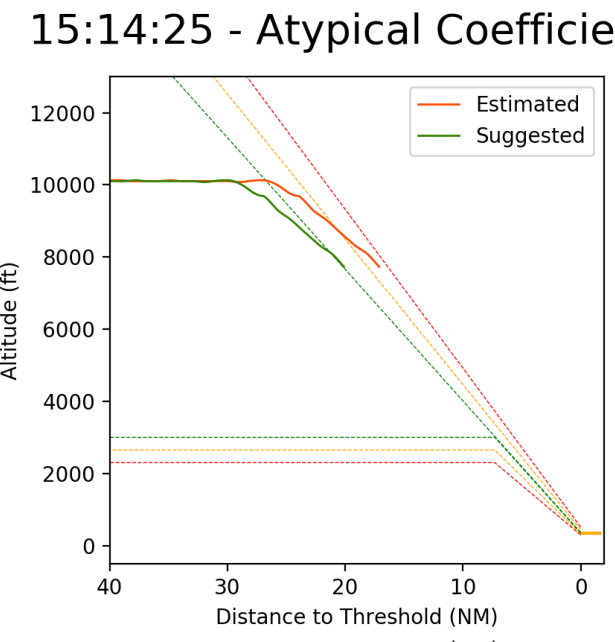

b)

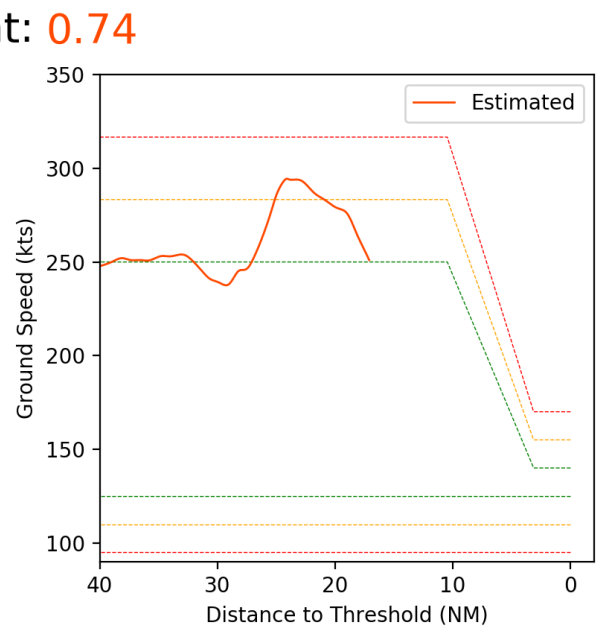

c)

Figure 11. Illustration of the Pegasus Airline Fight 2193 crash. Figure a) represents the 2D trajectory, Figure b) illustrates the altitude profile, and Figure c) the ground speed profile. The plane is on the base segment (a). Its ground speed is back to normal (c) but it is high on the glide path (c). The tool still suggests extending the trajectory (in green).

strong gusts of wind was crossing the area at the time of the accident [27], [28].

After what the Turkish Minister of Transport and Infrastructure described as a "hard landing", the plane failed to decelerate in time. After skidding at the eastern end of the runway, it slid about 60 metres and fell from a 30-40 metre high embankment and split into three sections. The forward part of the fuselage was particularly damaged during the incident. The passengers escaped from the aircraft through holes between the fuselage sections. A fire broke out and was quickly extinguished by the firefighters.

This flight presents an over-energy, and raises the question of energy management upstream. To what extent could it be detected that the flight presented excess energy and could remedial trajectories be proposed, or could a go-around be suggested ? To answer this question, the algorithm presented in the previous sections has been applied to the ADS-B trajectory of this flight from flightradar 24 .

The flight analysis is now presented. For context, the aircraft fly over the runway threshold at 15:18:30 UTC. At 15:12:17, 6 minutes before, our algorithm indicates an atypical coefficient of 0.73 materialized by the red dashed trajectory as shown in Figure 10 The aircraft turns in base leg and passes above the standard $3^{\circ}$ glide path with a ground speed of $250 \mathrm{kts}$. The algorithm proposes a suggested trajectory (in green dashed line) by slightly moving back the point of interception of the localizer.

At 15:14:25, two minutes later, the plane is still high on the 


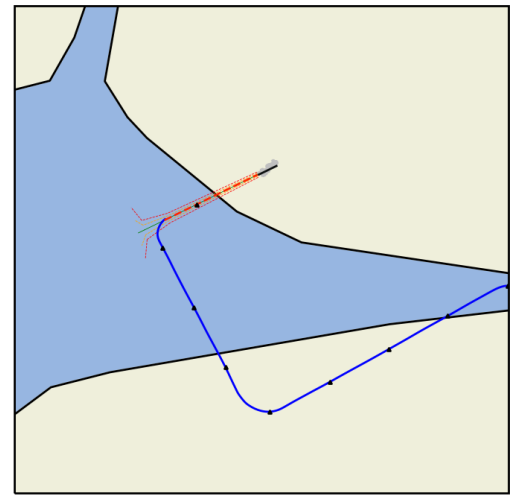

a)

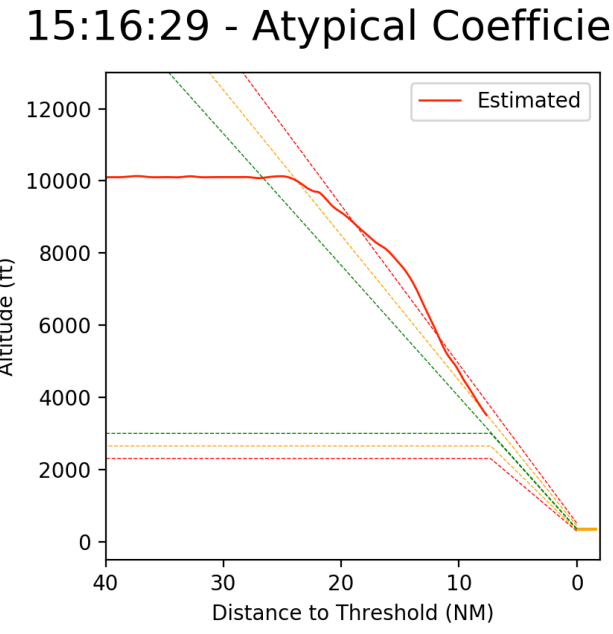

b)

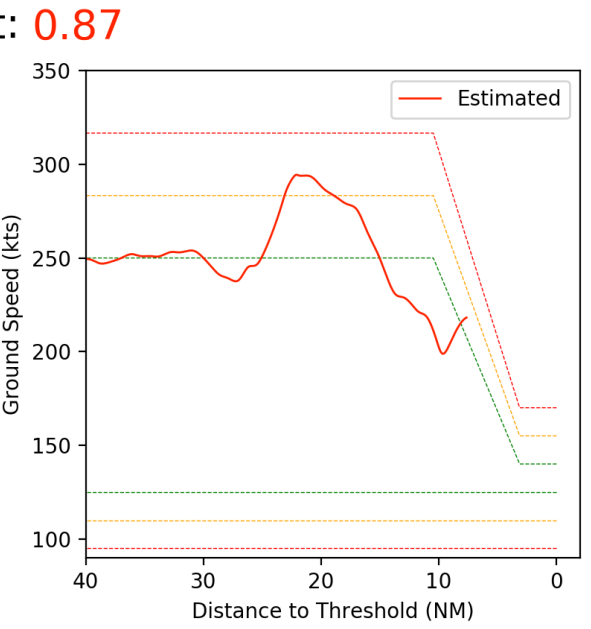

c)

Figure 12. Illustration of the Pegasus Airline Fight 2193 crash. Figure a) represents the 2D trajectory, Figure b) illustrates the altitude profile, and Figure c) the ground speed profile. The plane is on final approach (a), it is high on the glide path (b). Its ground speed is increasing (c) and its atypical score is 0.87 .

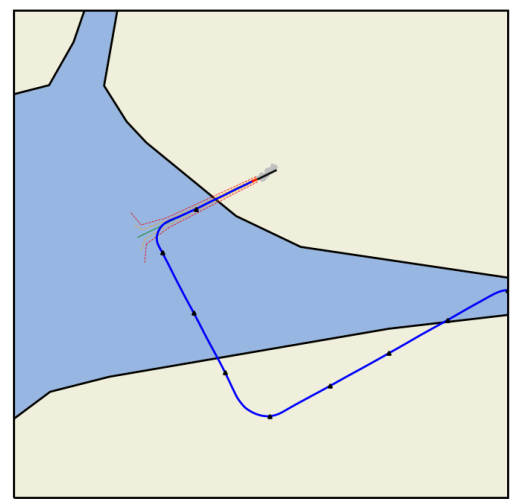

a)

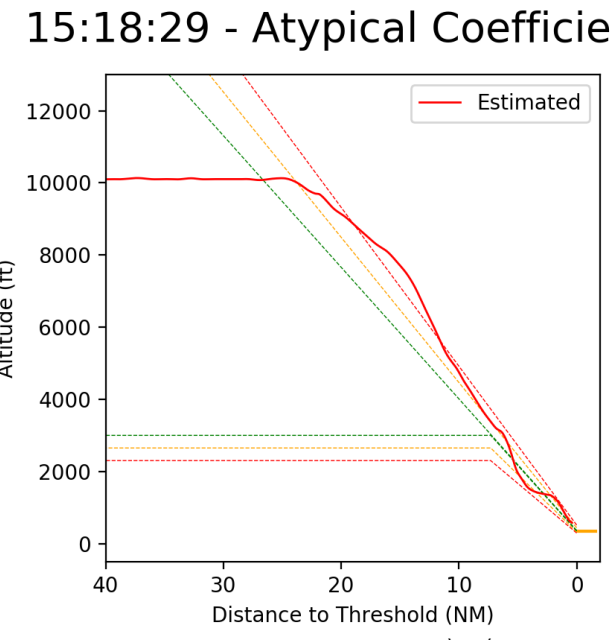

b)

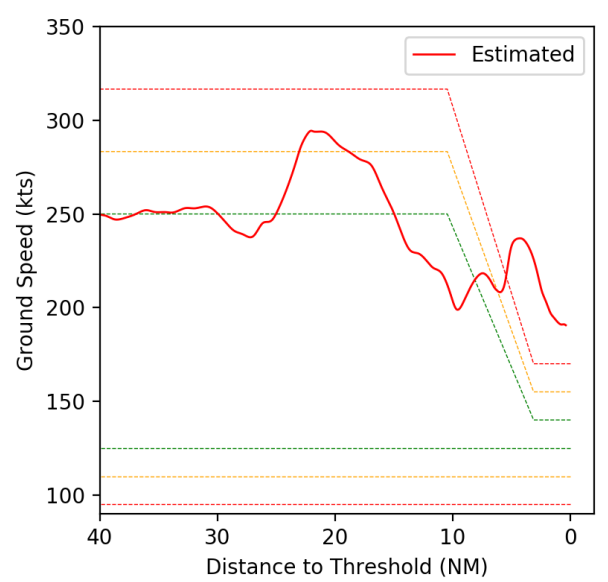

c)

Figure 13. Illustration of the Pegasus Airline Fight 2193 crash. Figure a) represents the 2D trajectory, Figure b) illustrates the altitude profile, and Figure c) the ground speed profile. The aircraft is 1NM from the runway threshold. The glide path management presents large variations, its ground speed is $190 \mathrm{kts}$ the atypicality did not decrease throughout the final.

glide path, the ground speed momentarily increased before coming back to $250 \mathrm{kts}$, probably due to a gust of wind. The coefficient of atypicality is still high (0.74), in the same way the algorithm proposes to lengthen the trajectory to dissipate the excess of energy as shown in Figure 11

At 15:16:29, the plane is on the localizer, the algorithm switches to backup net mode. The algorithm gives an atypicality coefficient of 0.83 . The plane is still a bit high on the glide path and its ground speed has just slightly increased to $215 \mathrm{kts}$ as shown in Figure 12.

Throughout the final approach, the atypicality coefficient will not fall below 0.8 and will cap at 1.0 from $1500 \mathrm{ft}$ to the runway threshold. It is also noted that the vertical profile shows strong variations, the aircraft momentarily passes below and then above the glide path. The ground speed is also very fluctuating up to 240kts, and finally 190kts when flying over the runway threshold as shown in Figure 13

In addition, the full post-operational study of the trajectory shows a non-conformity of the approach, the trajectory has been shortened and the localizer intercepted downstream of the interception chevrons. The on-board parameters are not available but the management of the vertical profile brings the question of flight stabilisation. In any case, the flight had been showing non-negligible signs of high energy for 6 minutes. The extreme weather conditions, the wet runway, could have prompted the controllers, if they had had access to such a tool, to suggest to the pilots a go-around and thus perhaps avoid the accident. 


\section{3-03-29 19:39:52 - Atypical Coefficient: 0.01}

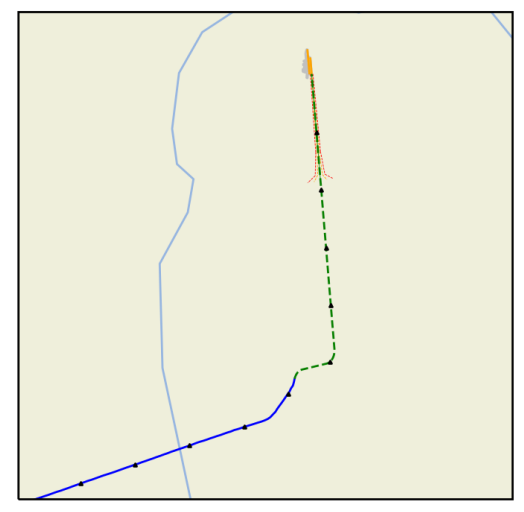

a)

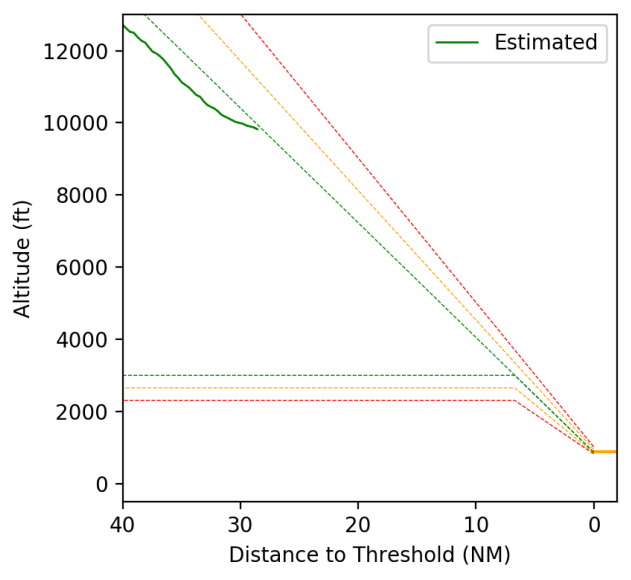

b)

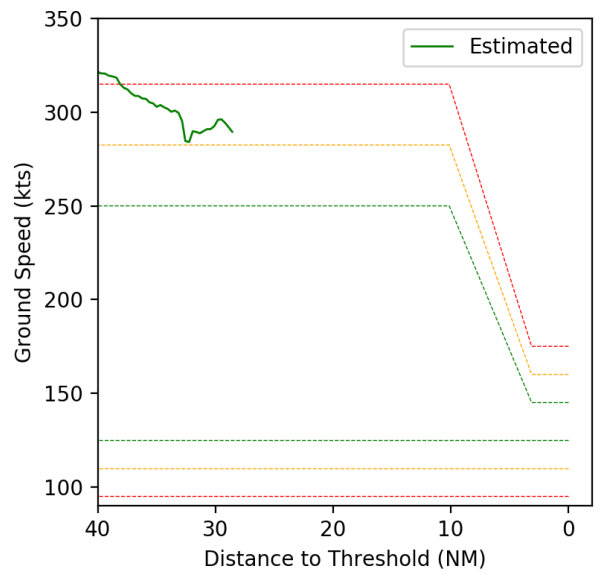

c)

Figure 14. Illustration of the Hermes Airline Fight 7817 crash. Figure a) represents the 2D trajectory, Figure b) illustrates the altitude profile, and Figure c) the ground speed profile. The crew follows the localizer interception heading given by the Air Traffic Controller and requests permission to deviate its trajectory by $10^{\circ}$ left to avoid a cloud a). The aircraft's ground speed is slightly high (c) and it is still under the glide path (b).The tool indicates that the aircraft is in a typical situation.

\section{3-03-29 19:42:54 - Atypical Coefficient: 0.75}

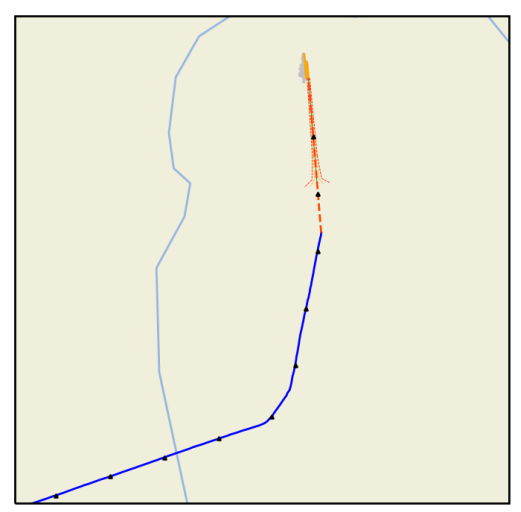

a)

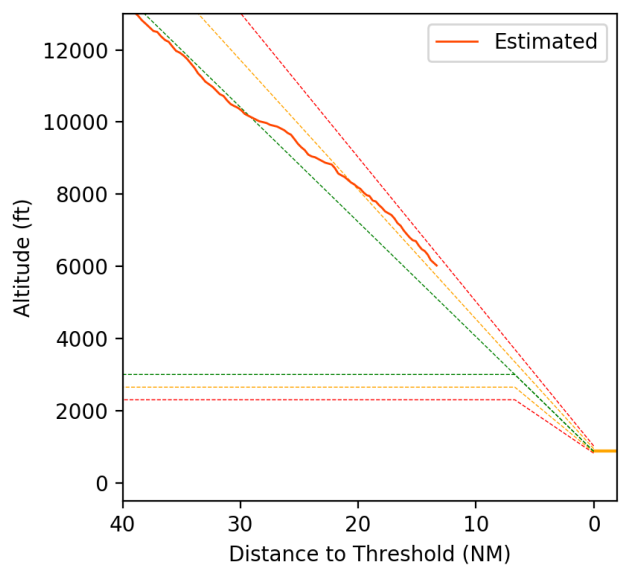

b)

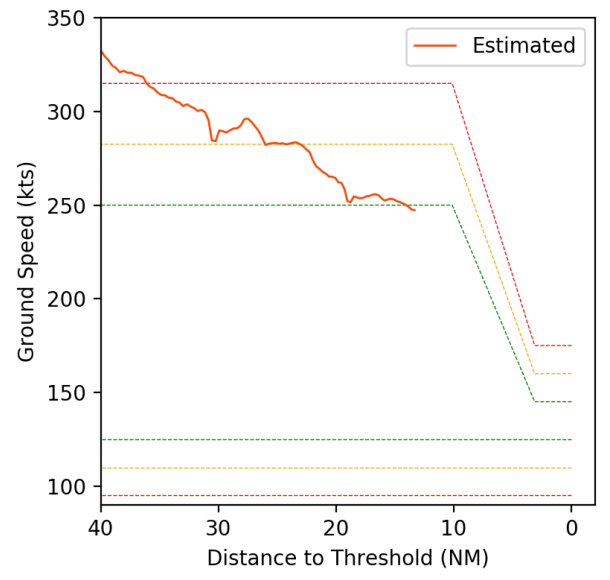

c)

Figure 15. Illustration of the Hermes Airline Fight 7817 crash. Figure a) represents the 2D trajectory, Figure b) illustrates the altitude profile, and Figure c) the ground speed profile. The aicraft intercepts the runway extended certerline. The deviation of $10^{\circ}$ right, shortened the track a), the plane is now above the glide path b). The aircraft's ground speed is around $250 \mathrm{kts}$ (c). The tool indicates an atypical situation due to an excess of potential energy.

\section{Hermes Airlines flight 7817}

The report of the French Bureau d'Enquêtes et d'Analyse (BEA) [29], in charge of investigating this crash describes the accident as follows.

The crew flew a category 1 (CAT I) ILS approach on runway 36R with an Airbus A321 at Lyon Saint-Exupéry aerodrome. The weather conditions were such that low visibility operating procedures (LVP) prevailed.

As the aircraft crossed the stabilization height at $1000 \mathrm{ft}$, the speed of the aircraft was $57 \mathrm{kt}$ higher than the approach speed. At $140 \mathrm{ft}$, an inappropriate increase in thrust by autothrust keeps the aircraft at a high speed.

The flare is long and the aircraft touches down on the runway 1,600 metres past threshold 36R. The aircraft exited the runway longitudinally and came to rest about 300 metres past the opposite threshold.

The following analysis of the flight by the atypicality algorithm was performed on the radar data recorded by the French Air Navigation Service Provider (ANSP).

At 19:39:52, the aircraft follows the localizer interception heading given by the Air Traffic Controller. In order to avoid a cloud, the crew requested permission to deviate its trajectory by $10^{\circ}$ left. At this moment, the aircraft is in a typical situation the atypical coefficient is 0.01 . The aircraft is just below glide path with a slightly high ground speed (280 kts) but the remaining distance leaves a large margin to reduce speed (see Figure 14). 


\section{3-03-29 19:44:22 - Atypical Coefficient: 0.88}

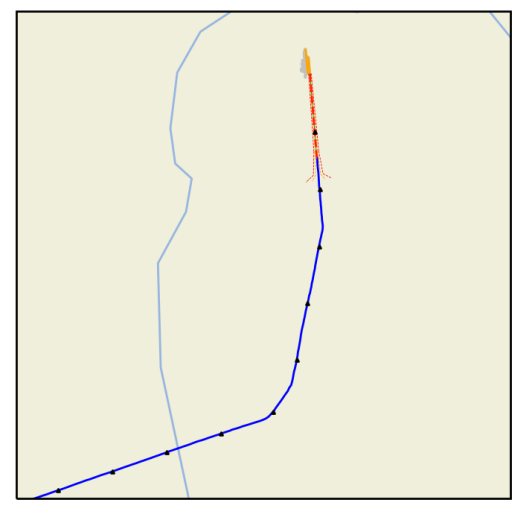

a)

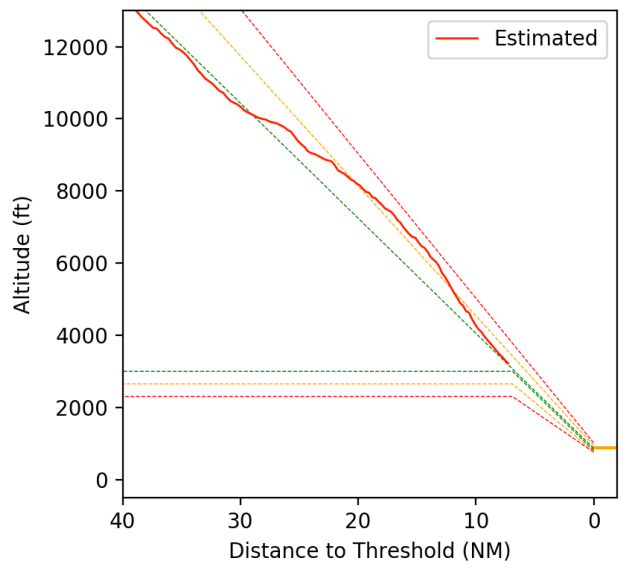

b)

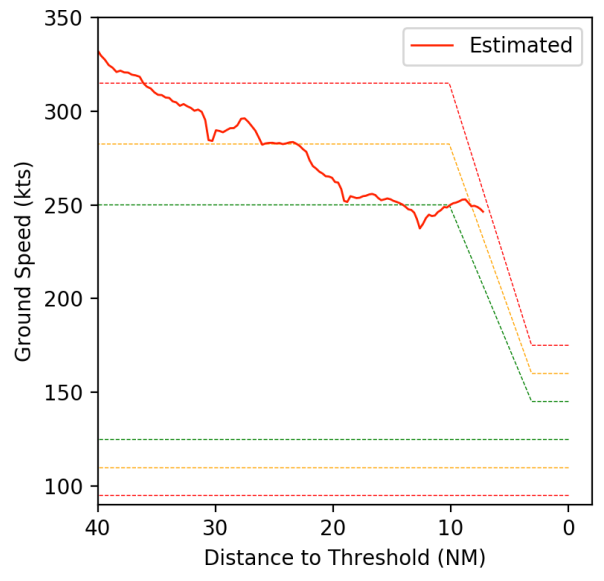

c)

Figure 16. Illustration of the Hermes Airline Fight 7817 crash. Figure a) represents the 2D trajectory, Figure b) illustrates the altitude profile, and Figure c) the ground speed profile. The plane has just recovered the glide path a). However, the potential energy b) has been transformed into kinetic energy and there is a slight increase of the ground speed towards $260 \mathrm{kts} \mathrm{c)}$. The atypicality increases around 0.88 due to an excess of kinetic energy.

\section{3-03-29 19:45:59 - Atypical Coefficient: 1.0}

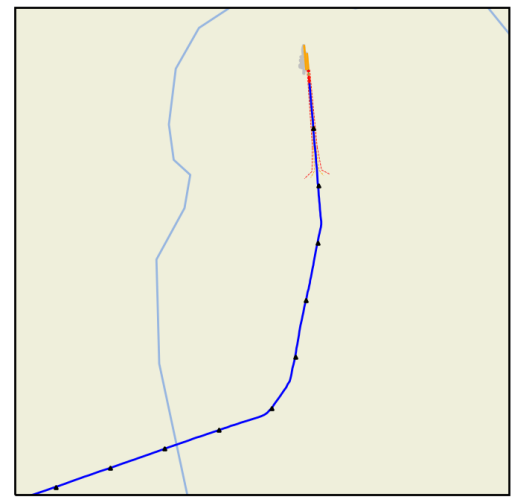

a)

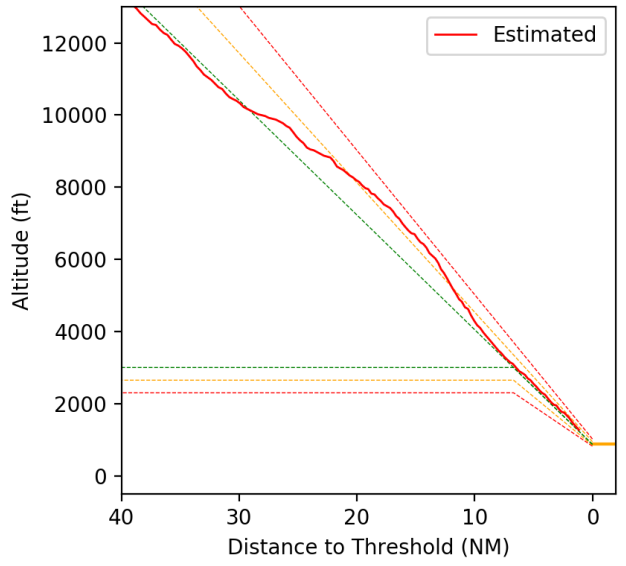

b)

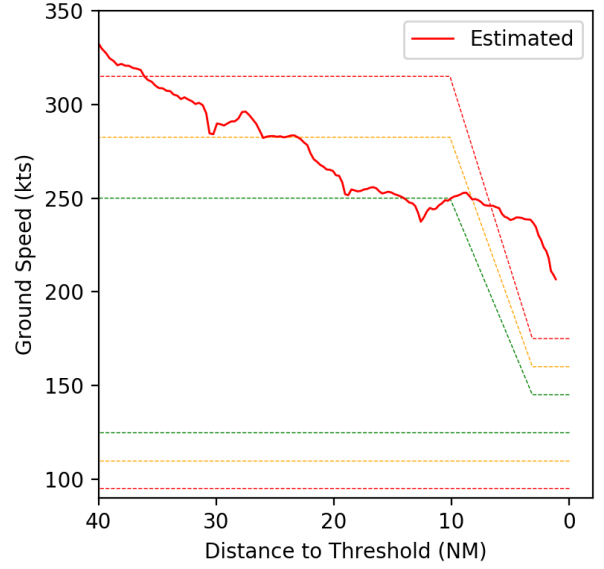

C)

Figure 17. Illustration of the Hermes Airline Fight 7817 crash. Figure a) represents the 2D trajectory, Figure b) illustrates the altitude profile, and Figure c) the ground speed profile. The aircraft is about $3 \mathrm{NM}$ from the runway threshold a). Its atypicality peaks at 1.0 because of a very high ground speed of 210 kts c), although decreasing. The aircraft is not stabilized with a very high speed and nevertheless continues its approach.

At 19:42:54, the plane intercepts the runway extended certerline. The deviation of $10^{\circ}$ right, shortened the track, the plane is now above the glide path. Its ground speed is $250 \mathrm{kts}$. The atypicality is 0.75 due to an excess of potential energy. (see Figure 15).

At 19:44:22, the plane has just recovered the glide path. However the potential energy has been transformed into kinetic energy and there is a slight increase of the ground speed towards 260kts. The atypicality increases around 0.88 due to an excess of kinetic energy (see Figure 16).

At 19:45:59, the aircraft is about 3NM from the runway threshold. Its atypicality peaks at 1.0 because of a very high ground speed of $210 \mathrm{kts}$, although decreasing. The aircraft is not stabilized with a very high speed and nevertheless continues its approach (see Figure 17).

The study based on the algorithm shows that an energy atypicality due to excessive energy appeared as early as 13NM before the runway threshold and continued throughout the final approach. The tool therefore shows the possibilities of anticipation and can be seen as a situation awareness alerting system.

\section{Air India Express flight 1344}

On August, 7 2002, a B737 Air India Express Flight 1344 was intented to land at Calicut International Airport [30]. The approach was for runway 28 , but two landings were aborted due to tailwind, and the aircraft circled, awaiting clearance, before landing on runway 10. Due to the monsoon 


\section{0-08-07 14:04:42 - Atypical Coefficient: 0.0}

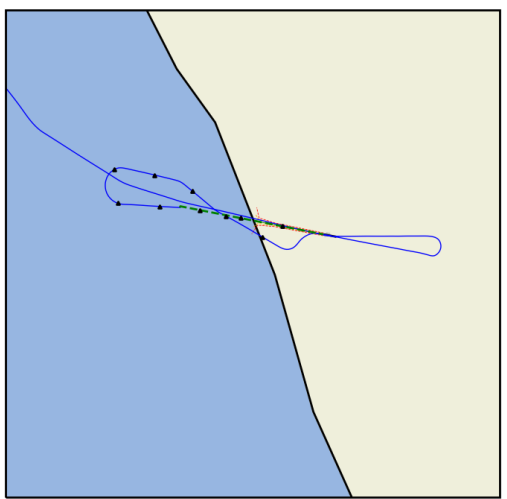

a)

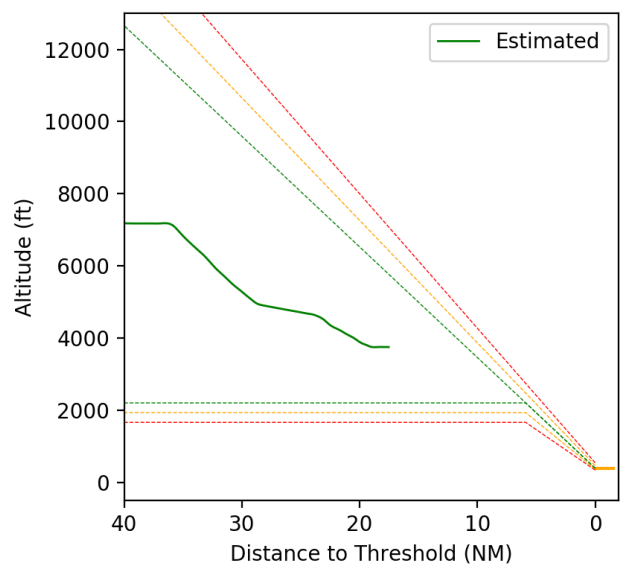

b)

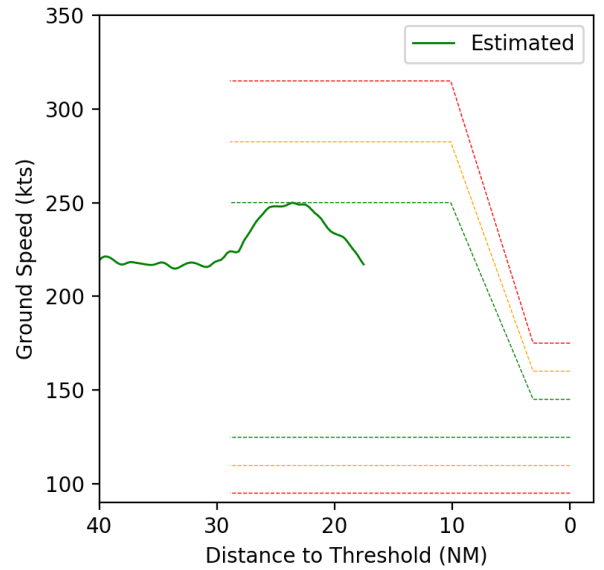

C)

Figure 18. Air India Express Fight 1344 lateral, altitude and speed profiles. The aircraft intercepts the runway extended center line (a). The aircraft's ground speed and altitude profile are nominal (a and c). The tool indicates that the aircraft is in a typical situation.

2020-08-07 14:08:02 - Atypical Coefficient: 0.97

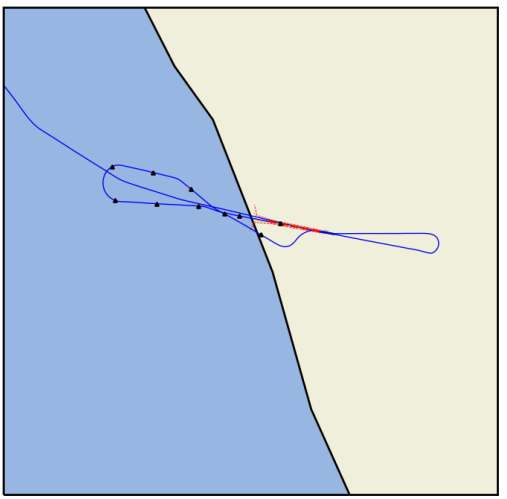

a)

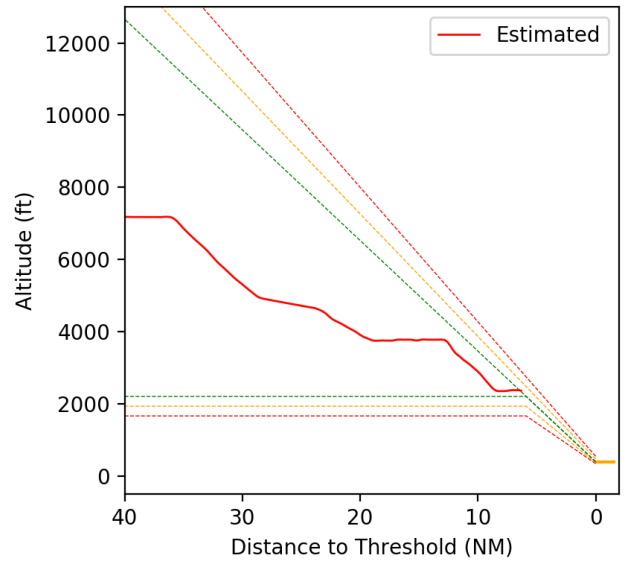

b)

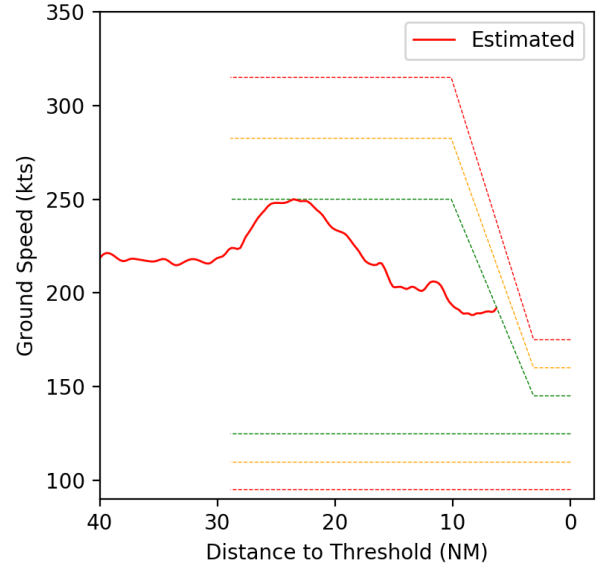

c)

Figure 19. Air India Express Fight 1344 lateral, altitude and speed profiles. The altitude profile is nominal however, its ground speed is around 200kts with no sign of reduction. The atypical coefficient has increased up to 0.97 underlying an atypical variation leading the aircraft to high energy.

and flooding in Kerala at the time, poor weather conditions reduced the visibility at the time of landing to $2000 \mathrm{~m}(6600$ $\mathrm{ft})$. Runway 28 was in use, and on the first attempt to land, the pilot could not see the runway and requested runway 10 . On the second attempt on Runway 10 at 2860 m (9 $380 \mathrm{ft}$ ), the aircraft landed near Taxiway " $\mathrm{C}$ ", which is approximately

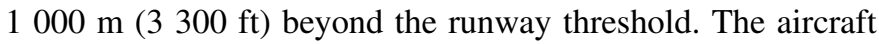
did not stop short of the end of the runway and plunged 9 to

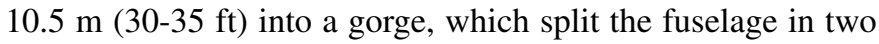
at impact. A total of 184 passengers, four cabin crew and two cockpit crew were on board. Eighteen people died in the crash (16 passengers and both pilots) and more than 100 people were injured. Additionally, bad weather conditions with tail wind in final approach and a wet runway were observed.

Using the FlightRadar24 ADS-B data, the replay methodology will be apply to analyse the final attempt.
At 14:04:42, the aircraft intercepts the runway extended center line, the ground speed, the altitude profile and the atypical coefficient are nominal (see Figure 18).

At 14:08:02, the aircraft intercepts the glide path, the altitude profile is nominal however, its ground speed is around 200kts with no sign of reduction. The atypical coefficient has increased up to 0.97 underlying an atypical variation leading the aircraft to high energy (see Figure 19.

At 14:08:54, the aircraft descends on the glide path, the ground speed has started to reduce down to $175 \mathrm{kts}$. The atypical coefficient is back to green areas(0.09). The reduction of the energy returns the aircraft to a less atypical state (see Figure 20].

At 14:09:30, the ADS-B data stopped at 1.6NM to the runway threshold. The aircraft is still on the glide path. However, the ground speed is not reducing anymore and 


\section{0-08-07 14:08:54 - Atypical Coefficient: 0.09}

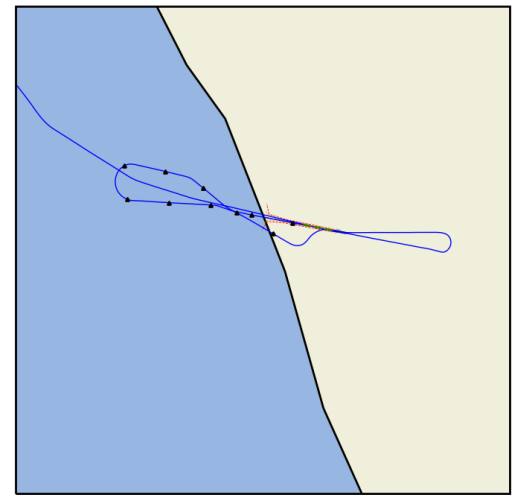

a)

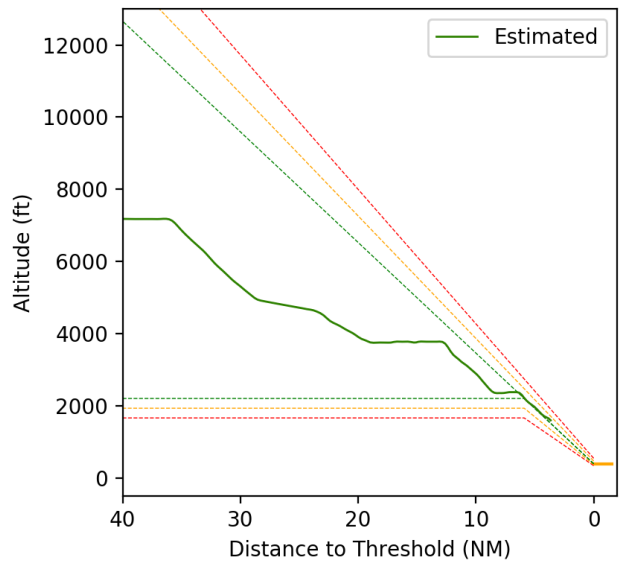

b)

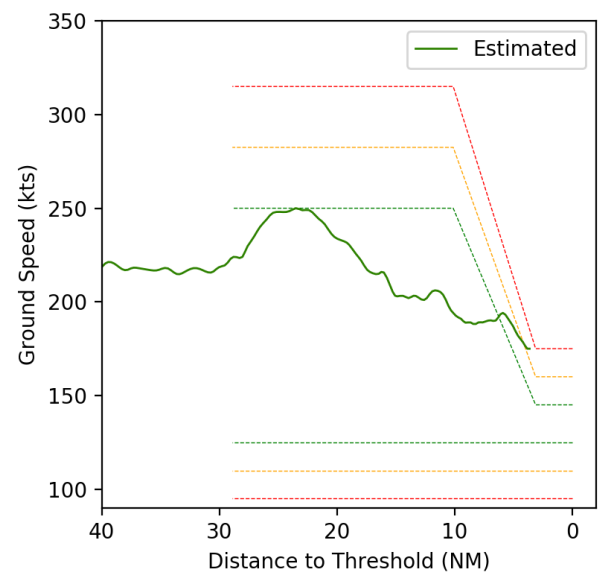

c)

Figure 20. Air India Express Fight 1344 lateral, altitude and speed profiles. The aircraft descends on the glide path, the ground speed has started to reduce down to $175 \mathrm{kts}$. The atypical coefficient is back to green areas $(0.09)$. The reduction of the energy returns the aircraft to a less atypical state

\section{0-08-07 14:09:30 - Atypical Coefficient: 0.96}

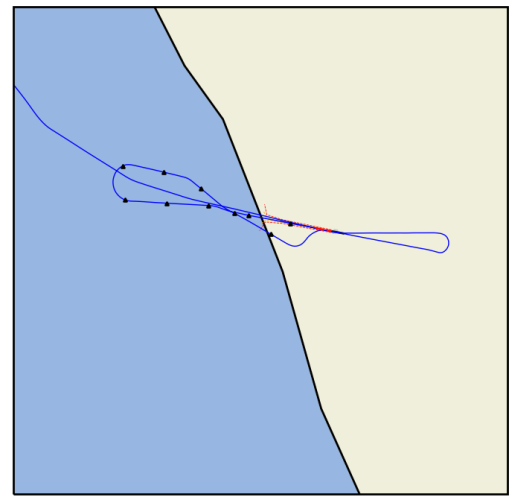

a)

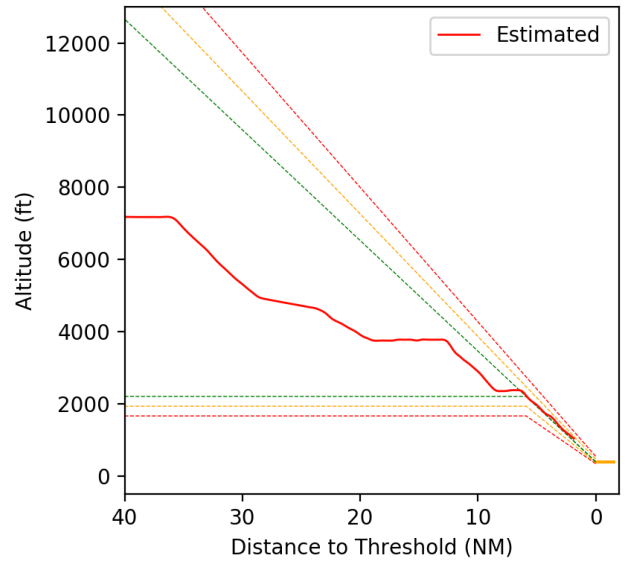

b)

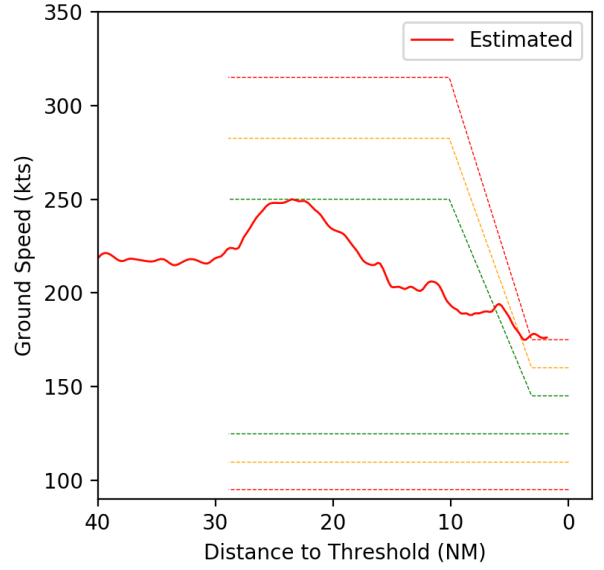

c)

Figure 21. Air India Express Fight 1344 lateral, altitude and speed profiles. The ADS-B data stopped at $1.6 \mathrm{NM}$ to the runway threshold. The aircraft is still on the glide path. However, the ground speed is not reducing anymore and stagnates at $175 \mathrm{kts}$. The atypical coefficient increased up to 0.96 again underlying a high kinetic energy

stagnates at $175 \mathrm{kts}$. The atypical coefficient increased up to 0.96 again underlying a high kinetic energy (see Figure 20).

\section{Discussions}

With this proposal, different questions immediately come to mind and have been raised by the different operators (ATC and airlines) to whom the model has been presented.

First of all, the notion of false positives is crucial. Indeed, in the case of real time use by air traffic controllers, it is not possible for too many warnings to appear. This implies an appropriate calibration which could be done by coupling with other statistical methods. It is nevertheless important to point out that high atypical scores represent a situation with very low, if not zero, frequency in the historical data set. In other words, if the atypicality score is high, it implies that only very few flights in the learning set have performed this energy management at this estimated remaining distance.

The proposed interface is not necessarily the one that would be suitable for air traffic controllers. One could for example imagine interception chevrons with variable position. If a direct trajectory from current position induces a high energy, the interception chevron would be pushed back to the suggested situation.

Concerning the energy management on approach, the work carried out previously [11] has shown that one out of two atypical flights between 5NM and the runway threshold are unstabilized. Calibration could therefore be considered by phase of flight and be more severe when approaching the runway threshold. The energy model could also integrate rotational energy in order to better analyze transitions between 
straight lines and curves. Additional information from machine learning tools [31] could help understanding on-board behaviours.

Secondly, the tool is placed in the framework of artificial intelligence, which implies an elaboration of the model from a training set. On this subject, a road map has just been published by EASA : [32]. It seems obvious that such a tool, if used in real time, must follow the guidelines of the road map to insure the trusworthiness of AI. In addition, such tools could lead to legal liabilities and therefore imply the implementation of detailed operational manuals and procedures.

Nevertheless, a less critical and simpler to implement use is condisered by airlines in the framework of flight data analysis. Indeed, this type of tool presents a major advantage for the training and analysis of flights in replay mode. It allows operators to highlight potentially unmonitored flight events and above all is a pedagogical means of making crews aware of the stakes of energy management during approach and landing. A Study carried out during COVID-19 crisis have shown an increased number of atypical behaviours during low traffic periods [33].

\section{CONCLusions}

In this paper a tool for detecting atypical aircraft approaches was presented. The major contribution is the real-time extension of a post-operational algorithm using Dubins paths. Two underlying uses have been presented and applied to aircraft crashes. First, an estimation of the current state of the aircraft by considering that the aircraft makes a direct to the interception chevrons. Second, in the case where the previous estimate presents a high energy state, a trajectory is suggested to bring the aircraft back to a nominal energy state.

This methodology presents a major advance, giving directions to new situation awareness alerting systems. The use in real time must obviously be subject to adequate calibration and the development of operational procedures. However, a use in the framework of flight data analysis and flight safety training as well as a use by safety authorities for prevention and safety improvement is envisaged in the very short term.

Finally, future works will focus on the real time calibration of the methodology, the investigation of more cases and the existence and minimization of false positives. Additional researches could be lead on the development of an appropriate learning process and the use of complementary methods in order to obtain a robust model meeting the safety requirement set by the EASA road-map. Other extensions could be made to improve the trajectory generation process, by extending a 3D trajectory, or by integrating the atypicality coefficient in a dedicated control model. Finally, it is also possible to consider the use of reinforcement learning to suggest an on-board trajectory that takes into account the aircraft configurations.

\section{REFERENCES}

[1] M. Tremaud, "Getting To Grips With ALAR," tech. rep., Airbus Industrie, Oct. 2000. Available at https://www.cockpitseeker.com/wp-content/ uploads/goodies/ac/a320/pdf/data/GettingToGripsWithALAR.pdf

[2] IATA, "2036 Forecast Reveals Air Passengers Will Nearly Double to 7.8 Billion," Oct. 2017. Available at https://www.iata.org/pressroom/pr/ pages/2017-10-24-01.aspx
[3] DGAC, "Safety state program, 2009-2013," 2009. Available at https://www.ecologique-solidaire.gouv.fr/sites/default/files/DGAC Plan-Strategique_2009-2013_FR.pdf

[4] DGAC, "Safety state program, horizon 2018," 2013. Available at https://www.ecologique-solidaire.gouv.fr/sites/default/files/ DGAC-PS-2018-FR-WEB.pdf

[5] DGAC, "Safety state program, horizon 2023," 2019. Available at https://www.ecologique-solidaire.gouv.fr/sites/default/files/DSAC_ PlanHorizon_2023_FR.pdf

[6] DGAC, “Risk portfolio, ssp 2009-2013,” $2010 . \quad$ Available at https://www.ecologique-solidaire.gouv.fr/sites/default/files/ Cartographie_Risques_10_2010.pdf

[7] Centro de Publicaciones, Ministerio de Fomento, "Report A-029/2011, Accident Involving a Bombardier CL-600-2b19 (CRJ200), Registration EC-ITU, Operated by Air Nostrum, at the Barcelona Airport, on 30 July 2011," tech. rep., Comisión de Investigación de Accidentes e Incidentes de Aviación Civil, Madrid, 2013. Available at https://www.fomento. gob.es/NR/rdonlyres/0E877F5B-5703-4AF3-95D9-3C6B1B8A2899/ 118577/2011_029_A_ENG.pdf

[8] C. A. Hart, R. L. Sumwalt, M. R. Rosekind, and E. F. Weener, "Descent Below Visual Glidepath and Impact With Seawall Asiana Airlines Flight 214 Boeing 777-200er, HL7742 San Francisco, California July 6, 2013," tech. rep., National Transportation Safety Board, 2014. Available at https://www.ntsb.gov/investigations/AccidentReports/ Reports/AAR1401.pdf

[9] Y. Jiao, H. Sun, C. Wang, and J. Han, "Research on unstable approach detection of civil aviation aircraft," Procedia computer science, vol. 131, pp. 525-530, 2018.

[10] G. Jarry, D. Delahaye, F. Nicol, and E. Feron, "Aircraft atypical approach detection using functional principal component analysis," Journal of Air Transport Management, vol. 84, p. 101787, 2020.

[11] G. Jarry, D. Delahaye, and E. Féron, "Trajectory approach analysis: A post-operational aircraft approach analysis tool," 2019.

[12] G. Jarry, N. Couellan, and D. Delahaye, "On the use of generative adversarial networks for aircraft trajectory generation and atypical approach detection," 2019.

[13] L. Li, S. Das, R. John Hansman, R. Palacios, and A. N. Srivastava, "Analysis of flight data using clustering techniques for detecting abnormal operations," Journal of Aerospace information systems, vol. 12, no. 9, pp. 587-598, 2015.

[14] L. Li, R. J. Hansman, R. Palacios, and R. Welsch, "Anomaly detection via a gaussian mixture model for flight operation and safety monitoring," Transportation Research Part C: Emerging Technologies, vol. 64, pp. 45-57, 2016.

[15] L. Li, M. Gariel, R. J. Hansman, and R. Palacios, "Anomaly detection in onboard-recorded flight data using cluster analysis," in 2011 IEEE/AIAA 30th Digital Avionics Systems Conference, pp. 4A4-1, IEEE, 2011.

[16] S. Das, B. L. Matthews, A. N. Srivastava, and N. C. Oza, "Multiple kernel learning for heterogeneous anomaly detection: algorithm and aviation safety case study," in Proceedings of the 16th ACM SIGKDD international conference on Knowledge discovery and data mining, pp. 47-56, 2010.

[17] M. Sharma, K. Das, M. Bilgic, B. Matthews, D. Nielsen, and N. Oza, "Active learning with rationales for identifying operationally significant anomalies in aviation," in Joint European Conference on Machine Learning and Knowledge Discovery in Databases, pp. 209-225, Springer, 2016.

[18] A. Nanduri and L. Sherry, "Anomaly detection in aircraft data using recurrent neural networks (rnn)," in 2016 Integrated Communications Navigation and Surveillance (ICNS), pp. 5C2-1, Ieee, 2016.

[19] R. Andreu Altava, J. C. Mere, D. Delahaye, and T. Miquel, "Graphsearch descent and approach trajectory optimization based on enhanced aircraft energy management," in AIAA Aviation 2019 Forum, p. 3618, 2019.

[20] A. Pritchett, "Reviewing the role of cockpit alerting systems," in Human Factors and Aerospace Safety: An International Journal: No. 1, pp. 538, Taylor and Francis, 2017.

[21] N. P. Singh, S. K. Goh, and Sameer Alam, "Real-time Unstable Approach Detection Using Sparse Variational Gaussian Process," in 1st International Conference on Artificial Intelligence and Data Analytics for Air Transportation (AIDA-AT 2020), 2020.

[22] L. E. Dubins, "On curves of minimal length with a constraint on average curvature, and with prescribed initial and terminal positions and tangents," American Journal of mathematics, vol. 79, no. 3, pp. 497-516, 1957. 
[23] J.-D. Boissonnat, A. Cérézo, and J. Leblond, "Shortest paths of bounded curvature in the plane," Journal of Intelligent and Robotic Systems, vol. 11, no. 1-2, pp. 5-20, 1994.

[24] L. S. Pontryagin, Mathematical theory of optimal processes. Routledge, 2018.

[25] X.-N. Bui, J.-D. Boissonnat, P. Soueres, and J.-P. Laumond, "Shortest path synthesis for dubins non-holonomic robot," in Proceedings of the 1994 IEEE International Conference on Robotics and Automation, pp. 2-7, IEEE, 1994.

[26] H. Chitsaz and S. M. LaValle, "Time-optimal paths for a dubins airplane," in 2007 46th IEEE conference on decision and control, pp. 2379-2384, IEEE, 2007.

[27] "Three dead, 180 hurt as plane skids off runway," BBC News, Feb. 2020 Available at https://www.bbc.com/news/world-europe-51384667

[28] "Pegasus Airlines flight 2193 overruns runway in Istanbul," Feb. 2020. Availaible at : https://www.flightradar24.com/blog/ pegasus-airlines-flight-2193-overruns-runway-in-istanbul/

[29] B. d'Enquêtes et Analyses, "Rapport accident survenu le 29 mars 2013 sur l'aéroport de lyon saint-exupéry (69) à l'airbus a321 immatriculé sxbhs exploité par hermes airlines affrété par air méditerranée," tech. rep., Bureau d'Enquêtes et d'Analyses, 2015. Available at https://www.bea. aero/fileadmin/documents/docspa/2013/sx-s130329/pdf/sx-s130329.pdf

[30] "Air India Express Flight 1344," Wikipedia, Aug. 2020. Page Version ID: 972120506.

[31] G. Jarry, D. Delahaye, and E. Feron, "Approach and landing aircraft on-board parameters estimation with lstm networks," in 2020 International Conference on Artificial Intelligence and Data Analytics for Air Transportation (AIDA-AT), pp. 1-6, IEEE, 2020.

[32] "EASA Artificial Intelligence Roadmap 1.0 published I A human-centric approach to AI in aviation." https://www.easa.europa.eu/newsroom-andevents/news/easa-artificial-intelligence-roadmap-10-published. Library Catalog: www.easa.europa.eu.

[33] G. Jarry, D. Delahaye, and E. Feron, "Flight safety during covid19: A study of charles de gaulle airport atypical energy approaches," Transportation research interdisciplinary perspectives, vol. 9, p. 100327, 2021. 